\title{
Flapping Wing CFD/CSD Aeroelastic Formulation Based on a Co- rotational Shell Finite Element
}

\author{
Satish K. Chimakurthi ${ }^{* 1}$, Bret K. Stanford ${ }^{* * 2}$, Carlos E. S. Cesnik ${ }^{* 3}$, and Wei Shyy ${ }^{* 4}$ \\ *Department of Aerospace Engineering \\ University of Michigan, Ann Arbor, MI, 48109, U.S.A. \\ **Department of Mechanical and Aerospace Engineering \\ University of Florida, Gainesville, FL, 32611, U.S.A.
}

\begin{abstract}
Flexible flapping wings have garnered a large amount of attention within the micro aerial vehicle (MAV) community: a critical component of MAV flight is the coupling of aerodynamics and structural dynamics. This paper presents a computational framework for simulating shell-like wing structures flapping in incompressible flow at low Reynolds numbers in both hover and forward flight. The framework is developed by coupling an in-house co-rotational finite element structural dynamics solver suitable for small strain and large rotations, to an in-house pressure-based Navier-Stokes solver. The development of the computational structural dynamics (CSD) solver and its coupling with the computational fluid dynamics (CFD) solver is discussed in detail. Validation studies are presented for both the CSD and the aeroelastic solvers using different wing configurations. Structural dynamics solutions are presented for rectangular wings with either a prescribed plunge or a single degree-of-freedom flapping motion. The aeroelastic response is computed for two different wing configurations: 1) a thin-plate rectangular aluminum wing (aspect ratio 6) undergoing a single-axis large amplitude flapping motion and 2) a rectangular wing of NACA0012 cross-section (aspect ratio 6) under a pure plunge motion. Results are validated against available experimental data and those obtained from a different aeroelasticity framework previously developed by the authors.
\end{abstract}

\section{Introduction and Motivation}

Flapping wing micro air vehicles are envisioned as having a small maximum dimension $(\sim 15 \mathrm{~cm})$, flying at low speeds $(\sim 10 \mathrm{~m} / \mathrm{s})$ and equipped with the capabilities of a stable hover and vertical take-off. The rise and growth of these vehicles have been stimulated by the need for highly maneuverable and light-weight structures that are capable of undertaking reconnaissance missions within confined spaces. These vehicles are mostly biologically-inspired [13]. Good reviews of the state-of-the-art in this subject are given in Refs.[3, 4]. High speed movies and still photography/stroboscopy indicate that most biological flyers undergo orderly deformation in flight [5]: birds, bats, and insects all exploit the coupling between flexible wings and aerodynamic forces such that the wing deformations improve aerodynamic performance [6]. The interaction between unsteady aerodynamics and structural flexibility (fluid-structure interaction/aeroelasticity) could be of considerable importance for the development of micro air vehicles [1].

Computational aeroelastic studies of flapping wings within the literature are relatively limited [7-18],while CFD-based aeroelastic studies of flapping wings with any kind of prescribed dynamic wing motion are very scarce. A reasonably detailed literature review on the computational aeroelastic studies of flapping wings has been presented in [10]. Some of the efforts in the area that are not covered in that paper are discussed here. Kim et al. [7] presented a coupling method for the fluid-structure interaction analysis of a flexible flapping wing. The aerodynamic model was based on a modified strip theory improved to take into account a high relative angle of attack and dynamic stall effects induced by pitching and plunging motions. The details of the structural model are not furnished

\footnotetext{
${ }^{1}$ Doctoral candidate, satishkc@umich.edu, Member AIAA.

${ }^{2}$ Currently National Research Council Post-doctoral Fellow, AFRL, bstan@ufl.edu, Member AIAA.

${ }^{3}$ Professor, cesnik@umich.edu, Associate Fellow AIAA.

${ }^{4}$ Clarence L. "Kelly” Johnson Collegiate Professor and Chair, weishyy@umich.edu, Fellow AIAA.
} 
except that it considered large flapping motions and local elastic deformations. Their aeroelastic model was applied to a rectangular flapping wing and the results were validated with experimental data.

Liani [16] uses a potential flow based aeroelastic analysis of flapping wings, and discusses how the lift and thrust generated by a spring-restrained pitching/plunging airfoil could be enhanced as the excitation frequency of the prescribed motion approaches the resonance frequency. Several aerodynamic models were utilized, including an unsteady panel method (where the airfoil may be of arbitrary shape and thickness but the flow is assumed to be attached) and a vortex particle method, in which the assumption of the attached flow is relieved. Unger et al. [19] performed aeroelastic analysis of a flexible built-up airfoil (based on a seagull's hand foil) under a sinusoidal plunging/pitching motion by coupling a modified unsteady Reynolds-averaged Navier-Stokes (URANS) flow solver, which takes the flow transition into account, and a nonlinear finite element shell solver. The calculated deformations show good agreement with deformations measured in a wind tunnel.

Gogulapati et al. [18] couple a commercial finite element solver (MSC.Marc) and a potential flow model that uses a combined circulation/vorticity approach to compute unsteady aerodynamic loads. Preliminary aeroelastic response results indicate that, for the parameters considered in their study, the effect of aerodynamic loads is relatively minor compared to the effect of the inertial loads; wing flexibility is found to have a favorable effect on lift generation. Ho et al. [15] used the two-way coupling feature of a flow solver (CFD-ACE+) and the structural dynamics solver FEMSTRESS to link the aerodynamics and the structural dynamics (both the solvers are commercially available). Aeroelastic computations were done for flapping wings for a titanium leading edge spar and a parylene membrane skin, followed by experimental validation of the results. More recently, Yang [20] used a similar coupling for the aeroelastic analysis of a flapping insect wing and obtained a good correlation with experimental data for a microbat.

Previously, two different coupled aeroelasticity codes were developed by the authors [10]: salient features are presented in Table 1. While these codes have the potential to solve flapping wing aeroelasticity problems, there are inherent limitations within each code which limit their range of applicability. For example, the structural dynamics solver UM/NLABS used in the first coupled code was developed in-house and could be used to analyze structures undergoing geometrically nonlinear beam-like but only low-order plate-like dynamic deformations. Similarly, the CFD solver STREAM [21] was also developed in-house. Since the source codes for both were available, an implicit aeroelastic coupling was realized in addition to the basic explicit version [10]. The commercially available finite element (FE) solver MSC.Marc involved in the second coupled code could be used to analyze shell-structures. However, due to the non-availability of the source code and due to the fact that MSC.Marc does not allow exchanges with an external CFD solver more than once per coupled time-step, only an explicit coupling could be realized in that case. This may be a serious limitation for flapping wings: numerical instabilities have been encountered [22] due to added-mass effects when explicit coupling methods were used to study the interaction of thin-elastic structures in incompressible, viscous flows.

Table 1. List of previously developed computational aeroelasticity codes [10].

\begin{tabular}{||c||c||c|c||}
\hline coupled code & fidelity level & source availability & coupling scheme \\
\hline \hline $\begin{array}{c}\text { UM/NLABS }+ \\
\text { STREAM }\end{array}$ & $\begin{array}{c}\text { reduced order CSD, } \\
\text { CFD }\end{array}$ & in-house & explicit and implicit \\
\hline \hline MSC.Marc + STREAM & shell FE, CFD & $\begin{array}{c}\text { commercial CSD and in-house } \\
\text { CFD }\end{array}$ & explicit only \\
\hline
\end{tabular}

In order to analyze plate/shell-like structures flapping in incompressible, viscous flow within the low Reynolds number regime, while gaining full control over the aeroelastic coupling scheme, this paper proposes a computational aeroelasticity code that is completely based on in-house nonlinear CSD and CFD solvers. In this framework, a nonlinear shell finite element solver called UM/NLAMS ("University of Michigan's Nonlinear Membrane Shell Solver") which is based on a co-rotational coordinate formulation [23-37] is used for the nonlinear structural dynamics analysis. For the CFD analysis, the pressure-based Navier-Stokes solver STREAM is used, which works with multi-block structured grids. The aeroelasticity framework is based on a partitioned solution of flow and structural solvers capable of supporting implicit coupling [10]. The goal is only to develop a prototype environment that essentially includes the features of implicit aeroelastic coupling and the capability to model coupled shell/membrane-like flapping wing structures, and not to claim more efficiency than what is provided by the frameworks involving UM/NLABS and/or MSC.Marc. The key features of the proposed aeroelasticity framework are highlighted in Table 2. 
Table 2. Aeroelasticity code proposed for the current work.

\begin{tabular}{|c|c||c|c|}
\hline coupled code & fidelity level & source availability & coupling scheme \\
\hline UM/NLAMS+STREAM & shell FE, CFD & in-house & explicit and implicit \\
\hline
\end{tabular}

The co-rotational (CR) coordinate approach that is used in this work to develop the nonlinear structural dynamics solution was previously applied by several researchers to static modeling of structures undergoing large displacements/rotations and small deformations. Applications to the dynamics of shell structures, however, are very scarce in the literature $[32,36,38,39]$. As part of the current effort, the static co-rotational formulation for shells described in Refs. [29, 30,34] is adapted to include flexible multi-body dynamics [40, 41]. More specifically, the goals of the present work are: 1) to describe the development of a new in-house co-rotational structural dynamics solver (UM/NLAMS) that is capable of handling prescribed time-dependent boundary conditions, 2) to discuss the development of an implicit aeroelastic coupling [10] framework between UM/NLAMS and STREAM, and 3) to present preliminary validation studies for the CSD and the aeroelastic solvers.

The paper is organized as follows: in section II, the development of the proposed aeroelasticity framework is described in detail while discussing aspects related to the aeroelastic interface (coupling algorithm, CFD grid morphing, etc.), the theoretical formulation behind the new co-rotational structural dynamics solver UM/NLAMS, time-integration procedure for nonlinear problems via the generalized- $\alpha$ scheme, and a brief introduction to the governing equations of the flow solver (taking into account the moving boundary problem). In section III, validation studies are discussed for the stand-alone structural dynamics code and for the aeroelastic code involving STREAM. Specifically, the nonlinear aeroelastic response is presented for rectangular wing configurations with either a prescribed flapping or a plunging motion, for comparison with available reference data.

\section{Numerical Framework for Computational Aeroelasticity}

\section{Aeroelastic Solution}

The coupled solution is based on a time-domain partitioned solution process in which the nonlinear partial differential equations modeling the dynamic behavior of both fluid and structure are solved independently with boundary information (aerodynamic loads and structural displacements) being shared alternately. A schematic of the framework is shown in Figure 1. A dedicated interface module was developed to enable communication between the flow and the structure at the 3-D wetted surface (fluid-structure interface). Since the underlying software codes are developed in-house, the framework has an inherent capability to handle various types of coupling strategies [42, 43].

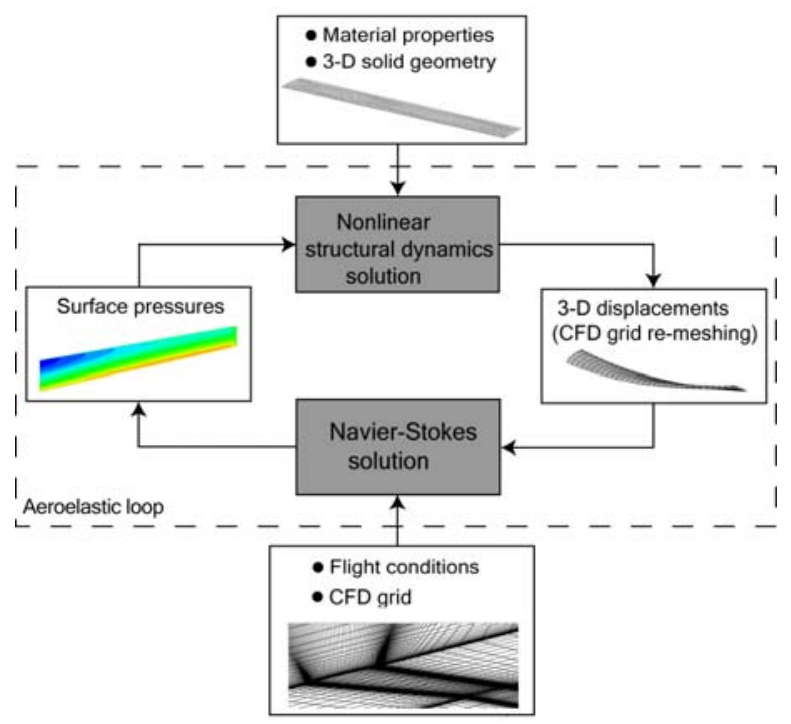

Figure 1. A schematic of the aeroelastic framework involving nonlinear CSD and CFD solvers. 


\section{Coupling algorithm and convergence criteria}

There are two different coupling algorithms within the purview of the aeroelasticity framework proposed here. In the explicit coupling approach, both solvers are called once per coupled time-step while exchanging data at the interface. In the implicit coupling approach, both the fluid and the structural solvers exchange data more than once per coupled time-step (see Figure 2). Between any two fluid-structure subiterations, the initial conditions in the solvers are not updated and hence a new coupled solution is obtained for the same time-step at the end of a subiteration. However, between the last fluid-structure subiteration of a coupled time-step and the first fluidstructure subiteration of the subsequent coupled time-step, the initial conditions in the solvers are updated and the solution is time-marched. The number of such fluid-structure subiterations is determined by a specified convergence criterion which could be judiciously chosen based on the problem at hand. Possible criteria include a check on the Euclidean or any other suitable norm of the entire solution vector either on the CFD or the CSD side, a check on the energy conservation at the fluid-structure interface, etc. The convergence criterion chosen in the current work is a check on the absolute difference in the Euclidean norm of the entire CSD solution vector computed in any two consecutive fluid-structure subiterations. It is important to note that the smoothness or possibly the accuracy of the coupled solution could depend upon the chosen criterion.

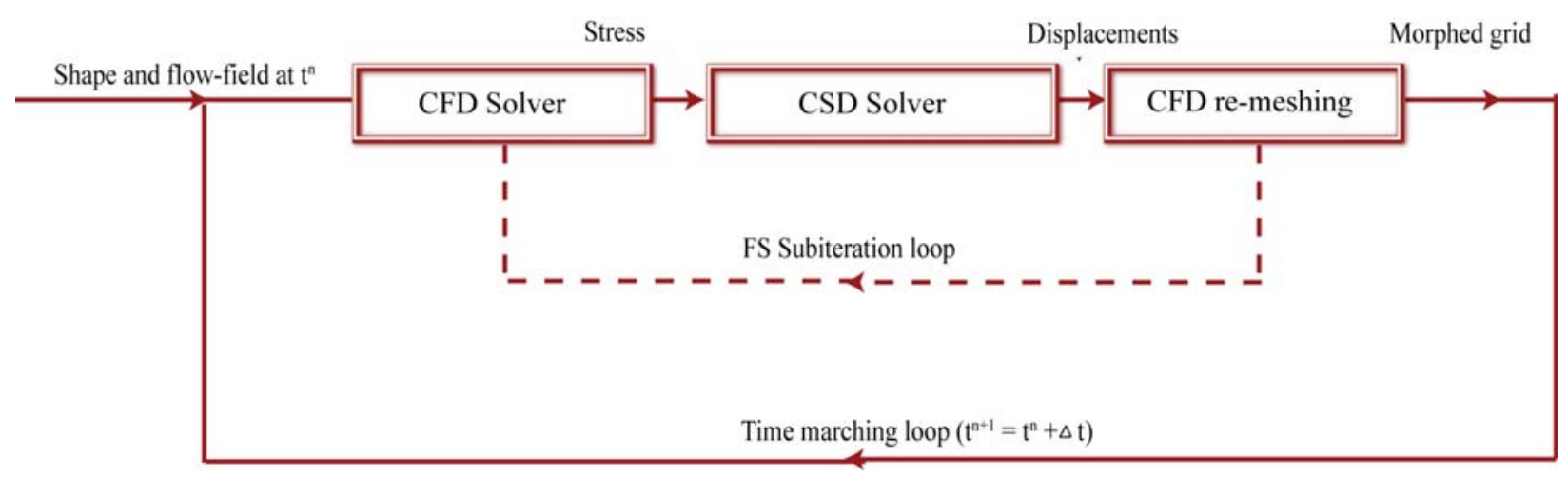

Figure 2. A schematic of the implicit coupling approach involving fluid-structure subiterations.

\section{Fluid-structure interpolation}

To perform interpolation of physical quantities between the fluid and the structural grids, the thin-plate spline [44] and the bilinear interpolation method [45] are included in the aeroelastic framework. The thin-plate spline is a global interpolation approach, and its distribution function is given by:

$$
\begin{aligned}
& \mathrm{H}\left(\mathrm{X}_{\mathrm{I}}\right)=\sum_{\mathrm{k}=1}^{\mathrm{N}} \alpha_{\mathrm{k}}\left|\mathrm{X}_{\mathrm{I}}-\mathrm{X}_{\mathrm{D}}\right|^{2} \log \left|\mathrm{X}_{\mathrm{I}}-\mathrm{X}_{\mathrm{D}}\right| \\
& \mathrm{X}=\mathrm{x} \hat{\mathrm{i}}+\mathrm{y} \hat{\mathrm{j}}
\end{aligned}
$$

where $X_{I}$ is a point in the receiver grid and $X_{D}$ is a point in the donor grid, where the interpolation coefficients $\alpha_{k}$ are known. $\mathrm{N}$ is the number of points in the donor grid. $\hat{i}$ and $\hat{j}$ are the unit vectors in the $\mathrm{x}$ and $\mathrm{y}$ directions respectively.

The bilinear interpolation is a local scheme: Figure 3 provides a schematic that shows how the solution at an interpolating point is obtained from the solution at the four supporting points around it. Assuming that $\left(\mathrm{x}_{1}, \mathrm{y}_{1}\right),\left(\mathrm{x}_{2}\right.$, $\left.\mathrm{y}_{1}\right),\left(\mathrm{x}_{2}, \mathrm{y}_{2}\right)$, and $\left(\mathrm{x}_{1}, \mathrm{y}_{2}\right)$ are the coordinates of nodes $1,2,3$, and 4 , respectively, the interpolated solution $\mathrm{p}_{\text {int }}$ at an arbitrary point $(\mathrm{x}, \mathrm{y})$ within the rectangle is given by the interpolation function below:

$$
\mathrm{p}_{\text {int }}=\mathrm{N}_{1} \mathrm{p}_{1}+\mathrm{N}_{2} \mathrm{p}_{2}+\mathrm{N}_{3} \mathrm{p}_{3}+\mathrm{N}_{4} \mathrm{p}_{4}
$$

where 


$$
N_{1}=\frac{\left(x_{2}-x\right)\left(y_{2}-y\right)}{\left(x_{2}-x_{1}\right)\left(y_{2}-y_{1}\right)}, N_{2}=\frac{\left(x-x_{1}\right)\left(y_{2}-y\right)}{\left(x_{2}-x_{1}\right)\left(y_{2}-y_{1}\right)}, N_{3}=\frac{\left(x-x_{1}\right)\left(y-y_{1}\right)}{\left(x_{2}-x_{1}\right)\left(y_{2}-y_{1}\right)}, N_{4}=\frac{\left(x_{2}-x\right)\left(y-y_{1}\right)}{\left(x_{2}-x_{1}\right)\left(y_{2}-y_{1}\right)}
$$

and $\mathrm{p}_{1}, \mathrm{p}_{2}, \mathrm{p}_{3}$, and $\mathrm{p}_{4}$ are the field information given at nodes $1,2,3$, and 4 respectively. This scheme applies only to cases where the donor grids are structured into four-noded quads. In this work, the thin-plate spline method is used for the interpolation of displacements and the bilinear scheme for the pressure loads. Velocities at the structural nodes are not interpolated onto the CFD mesh, as they are calculated by the CFD solver itself based on the displacements at two consecutive time-steps by using a first-order backward difference scheme to satisfy the geometric conservation law (GCL) [46].

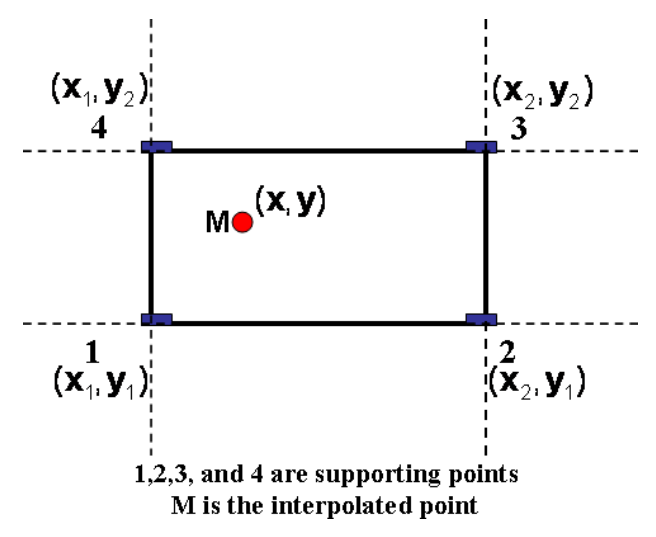

Figure 3. Bilinear interpolation geometric arrangement.

\section{CFD grid re-meshing/morphing}

As mentioned above, the CFD solver STREAM employs multi-block structured grids. For the grid morphing in the aeroelastic simulations, a master/slave strategy is used to establish a relationship between the moving surface points (master points) and vertices located at the grid blocks (slave points). The movement of the master points is based on the displacements obtained from the structural solver, while the movement of the slave points is in turn based on that of the master points. For this purpose, a simple but effective formula suggested by Hartwich and Agrawal [47], based on a spring analogy, is used and is given by:

$$
\overline{\mathrm{x}}_{\mathrm{s}}=\mathrm{x}_{\mathrm{s}}+\theta\left(\overline{\mathrm{x}}_{\mathrm{m}}-\mathrm{x}_{\mathrm{m}}\right)
$$

The subscripts $\mathrm{m}$ and $\mathrm{s}$ represent master and slave, respectively, the overbar indicates the new position. $\mathrm{x}_{\mathrm{s}}$ is a vector of the coordinates $\left(\mathrm{x}_{\mathrm{v}}, \mathrm{y}_{\mathrm{v}}, \mathrm{z}_{\mathrm{v}}\right)$ of a slave point and $\mathrm{x}_{\mathrm{m}}$ is that of a master point $\left(\mathrm{x}_{\mathrm{p}}, \mathrm{y}_{\mathrm{p}}, \mathrm{z}_{\mathrm{p}}\right)$. In this work, a Gaussian distribution function as suggested by Hartwich and Agrawal [47] is used for the decay function, $\theta$, given by:

$$
\theta=\exp \left\{-\beta_{\mathrm{c}} \min \left[\mathrm{f}_{\mathrm{m}}, \frac{\sqrt{\left(\mathrm{x}_{\mathrm{v}}-\mathrm{x}_{\mathrm{p}}\right)^{2}+\left(\mathrm{y}_{\mathrm{v}}-\mathrm{y}_{\mathrm{p}}\right)^{2}+\left(\mathrm{z}_{\mathrm{v}}-\mathrm{z}_{\mathrm{p}}\right)^{2}}}{\left(\varepsilon+\sqrt{\left(\overline{\mathrm{x}}_{\mathrm{p}}-\mathrm{x}_{\mathrm{p}}\right)^{2}+\left(\overline{\mathrm{y}}_{\mathrm{p}}-\mathrm{y}_{\mathrm{p}}\right)^{2}+\left(\overline{\mathrm{z}}_{\mathrm{p}}-\mathrm{z}_{\mathrm{p}}\right)^{2}}\right)}\right]\right\}
$$

where $\varepsilon$ is an arbitrary small number to eliminate divisions by zero. The coefficient $\beta_{\mathrm{c}}$ affects the stiffness: a larger value causes the block to behave more like a rigid body and a smaller value makes the mesh behave in a pliant fashion. Similarly, the factor $f_{m}$ in Eq. (1.5) also plays an important role in the re-meshing: for a fixed value of $\beta_{c}$, a smaller $f_{m}$ will make the mesh behave in a more pliant fashion and vice-versa. Once the displacements of the slave points are obtained, they are propagated throughout the entire grid using a transfinite interpolation technique. More details about the moving mesh algorithm can be obtained in Refs. [47-49].

\section{Coupled aeroelastic code}

A coupled code was achieved simply by compiling the object files of the individual solvers along with those of 
the interface routines (interpolation, morphing, etc.) to produce a single shared executable. This could then be ported to Linux work-stations without having to re-compile the code (unless certain machine-specific libraries are needed). This was possible in the current work due to the availability of the individual source codes. In cases where this is not possible, a relatively less efficient way of data transfer is obtained by reading and writing data files from one solver to the other at every iteration/time-step.

\section{Structural Dynamics Solution (UM/NLAMS)}

The nonlinear structural dynamics solution is based on a flexible multi-body type finite element analysis [38, $40,41]$ of a flapping wing. It relies on the use of a body-fixed floating frame of reference to describe the prescribed rigid body motion and on a co-rotational (CR) framework to account for geometric nonlinearities. The solution is implemented in the "University of Michigan's Nonlinear Membrane Shell Solver" (UM/NLAMS), written in Fortran 90. The CR formulation has generated a great amount of interest in the last decade. A comprehensive list of references that discuss this formulation is available in Ref. [40]. The idea of this approach is to decompose the motion into rigid body and pure deformational parts through the use of a local frame at each finite element which translates and rotates with the element [23]. The element's internal force components are first calculated relative to the co-rotational frame and are then transformed to a global frame using the co-rotational transformation matrix. The co-rotational frame transformation eliminates the element rigid body motion so that a linear deformation theory can be used [40]. Hence, the main advantage of the CR formulation is its effectiveness for problems with small strains but large rotations [50].

The co-rotational formulation can be applied in two different forms: total Lagrangian (CR-TL) and updated Lagrangian (CR-UL). In the CR-TL approach, the reference configuration is taken as the initial configuration, but translated and rotated in accordance with the motion of the co-rotating local system. In the CR-UL approach, the translated and rotated configuration at the previous time-step is taken as the reference configuration during the current time-step [31, 51]. A CR-TL approach will be followed in this work. Co-rotational formulations involving shell elements for flexible multi-body systems applications are given in Refs. [38, 52]. While the application of this method to problems concerning flapping wing aeroelasticity are not known to the authors, recent studies by Relvas and Suleman $[35,39]$ reported the development of a method involving the application of co-rotational theory to nonlinear aeroelasticity problems.

The three key issues identified during a literature survey concerning the use of a co-rotational formulation are: 1) the choice of a suitable local element frame, 2) the choice of a suitable anisotropic element (this is especially important for triangular shells since they are obtained as a superposition of membrane and plate models and several combinations are possible), and 3) parameterization of local and global rotations. The first issue is discussed in Refs. [23, 53, 54], among many others. In the current work, triangular elements will be used for the finite element discretization. The specific issues involved in choosing local element frames concerning the use of trianglular shell elements are discussed in Ref. [24], and the choice of a suitable linear element in Ref. [23]. The development of flapping wing dynamic finite-element equations of motion for thin shell structures is discussed next. The formulation is a proposed extension for flapping wing dynamics of the static co-rotational analysis of shell structures presented in Refs. [29, 30, 34].

\section{Derivation of flapping wing equations of motion}

Nonlinear finite element analysis of shell structures via a co-rotational approach to accommodate prescribed time-dependent boundary conditions involves several key steps outlined below:

\section{Definition of inertial, global, and local coordinate systems}

Several coordinate systems are required to fully describe the geometry and deformation of the shell structure. Figure 4 shows a schematic of a typical triangular shell finite element in its initial (undeformed) and the deformed configurations. A total of $2+\mathrm{N}_{\mathrm{e}}+\mathrm{N}_{\mathrm{n}}$ (where $\mathrm{N}_{\mathrm{e}}$ is the number of finite-elements and $\mathrm{N}_{\mathrm{n}}$ is the number of nodes in the discretized structure) coordinate systems are used in the analysis: an inertial frame that is always fixed in time ("I" in Figure 4), a floating frame (global) whose motion is known in the inertial frame by virtue of the prescribed rigid body motion of the structure ("g" in Figure 4), $\mathrm{N}_{\mathrm{e}}$ co-rotational frames (one for each element) that translate and rotate with the element as it deforms (" $E_{o}$ " and "E" in Figure 4), and $N_{n}$ nodal coordinate frames (one for each node) that are rigidly tied to their respective nodes and rotate with them ("S" $\mathrm{o}_{0}$ " and " $\mathrm{S}$ " in Figure 4). The final equations of motion are written with respect to the global frame. 


\section{Computation of inertial velocities and accelerations of a material point}

The position (in the inertial frame) of a material point $\mathrm{P}$ on the structure is given by:

$$
X=X_{R}+T_{I G} x_{g}
$$

where $\mathrm{X}$ is the position vector in the inertial frame, $\mathrm{X}_{\mathrm{R}}$ is the position vector of the structure's actuation point (or the origin of the flapping/global frame) in the inertial frame, $\mathrm{x}_{\mathrm{g}}$ is the position vector of $\mathrm{P}$ in the global frame, and $\mathrm{T}_{\mathrm{IG}}$ is a transformation matrix from global frame to the inertial frame. This matrix is a nonlinear function of the components of the rotation pseudo vector $\Psi$ [55], which defines the orientation of the global frame with respect to the inertial frame. The pseudo vector is defined as:

$$
\Psi=\psi \hat{p}
$$

Where $\psi$ is the magnitude of rotation and $\hat{\mathrm{p}}$ is the direction of rotation, defined as:

$$
\hat{\mathrm{p}}=\frac{\Psi}{\psi}=\left\{\begin{array}{l}
\hat{\mathrm{p}}_{\mathrm{x}} \\
\hat{\mathrm{p}}_{\mathrm{y}} \\
\hat{\mathrm{p}}_{\mathrm{z}}
\end{array}\right\}
$$

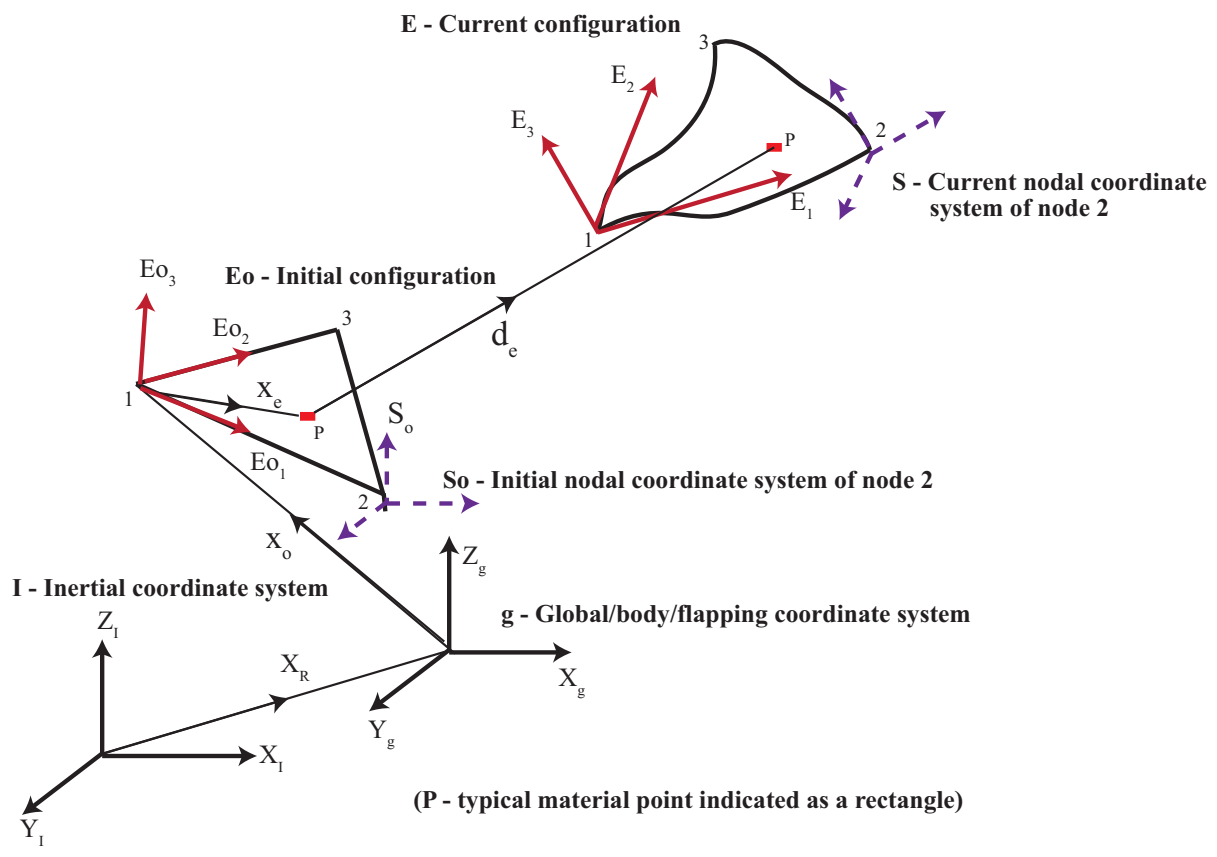

Figure 4. A schematic showing the undeformed and deformed configurations of a typical shell element and the various coordinate systems involved in the analysis.

In general, both the magnitude $\psi$ and the direction of rotation $\hat{\mathrm{p}}$ could be time-dependent. In the case where the direction of rotation is constant, the resultant motion of the tip of the pseudo vector will be in a plane. If the direction of rotation changes with time, the motion of the tip will be in $3 \mathrm{D}$ space. The former case is twodimensional and the latter is three-dimensional rotation [41]. The transformation matrix $\mathrm{T}_{\mathrm{IG}}$ is defined as in [56]:

$$
\mathrm{T}_{\mathrm{IG}}=\mathrm{I}+\tilde{\hat{\mathrm{p}}} \sin \psi+2(\tilde{\hat{\mathrm{p}}})^{2} \sin ^{2} \frac{\psi}{2}
$$


where $\mathrm{I}$ is a $3 \times 3$ identity matrix and the tilde indicates the skew-symmetric matrix of the vector $\hat{\mathrm{p}}$. The position vector of the material point with respect to the global coordinate system $\mathrm{x}_{\mathrm{g}}$ given in Eq. (1.6) can be written as :

$$
\mathrm{x}_{\mathrm{g}}=\mathrm{x}_{\mathrm{o}}+\mathrm{T}_{\mathrm{GE}}\left(\mathrm{x}_{\mathrm{e}}+\mathrm{d}_{\mathrm{e}}\right)
$$

where $x_{0}$ is the origin of an element frame in the undeformed configuration with respect to the global frame expressed as components in the global frame, $\mathrm{T}_{\mathrm{GE}}$ is the transformation matrix from element frame to the global frame, $\mathrm{x}_{\mathrm{e}}$ is the position vector of the point with respect to the element frame, and $\mathrm{d}_{\mathrm{e}}$ is the vector of displacements of the point with respect to the element frame. The position vector of the material point in the inertial frame given in Eq. (1.6) then becomes:

$$
X=X_{R}+T_{I G} x_{o}+T_{I G} T_{G E} x_{e}+T_{I G} T_{G E} d_{e}
$$

The time derivative of the transformation matrix is [56]:

$$
\dot{\mathrm{T}}_{\mathrm{IG}}=\Omega \mathrm{T}_{\mathrm{IG}}
$$

where $\Omega$ is a matrix defined as:

$$
\Omega=2 \dot{\hat{\mathrm{p}}} \hat{\mathrm{p}} \sin ^{2} \frac{\psi}{2}+\dot{\hat{\mathrm{p}}} \sin \psi+\hat{\mathrm{p}} \dot{ }
$$

The velocity and acceleration at a material point can then be computed as:

$$
\begin{gathered}
\dot{\mathrm{X}}=\dot{\mathrm{X}}_{\mathrm{R}}+\Omega \mathrm{T}_{\mathrm{IG}} \mathrm{x}_{\mathrm{o}}+\Omega \mathrm{T}_{\mathrm{IG}} \mathrm{T}_{\mathrm{GE}} \mathrm{x}_{\mathrm{e}}+\Omega \mathrm{T}_{\mathrm{IG}} \mathrm{T}_{\mathrm{GE}} \mathrm{d}_{\mathrm{e}}+\mathrm{T}_{\mathrm{IG}} \mathrm{T}_{\mathrm{GE}} \dot{\mathrm{d}}_{\mathrm{e}} \\
\ddot{\mathrm{X}}=\ddot{\mathrm{X}}_{\mathrm{R}}+(\dot{\Omega}+\Omega \Omega) \mathrm{T}_{\mathrm{IG}}\left(\mathrm{x}_{\mathrm{o}}+\mathrm{T}_{\mathrm{GE}} \mathrm{x}_{\mathrm{e}}+\mathrm{T}_{\mathrm{GE}} \mathrm{d}_{\mathrm{e}}\right)+2 \Omega \mathrm{T}_{\mathrm{IG}} \mathrm{T}_{\mathrm{GE}} \dot{\mathrm{d}}_{\mathrm{e}}+\mathrm{T}_{\mathrm{IG}} \mathrm{T}_{\mathrm{GE}} \ddot{\mathrm{d}}_{\mathrm{e}}
\end{gathered}
$$

\section{Computation of virtual work due to inertial forces}

The virtual work due to inertial forces for an element is given by:

$$
\delta \mathrm{W}=\rho \int_{\mathrm{V}} \delta \mathrm{X}^{\mathrm{T}} \ddot{\mathrm{X}} \mathrm{dV}
$$

where $\delta \mathrm{X}$ is the variation of the position vector, i.e.,

$$
\delta \mathrm{X}=\mathrm{T}_{\mathrm{IG}} \mathrm{T}_{\mathrm{GE}} \delta \mathrm{d}_{\mathrm{e}}
$$

The vector of displacements $d_{e}$ can be approximated as:

$$
\mathrm{d}_{\mathrm{e}}=\mathrm{Nq}_{\mathrm{e}}
$$

where $\mathrm{N}$ is a matrix of shape functions of size $3 \times 18$ and $\mathrm{q}_{\mathrm{e}}$ is the nodal degree of freedom vector of size $18 \mathrm{x} 1$ with respect to the element frame. The variation of the position vector now becomes:

$$
\delta \mathrm{X}=\mathrm{T}_{\mathrm{IG}} \mathrm{T}_{\mathrm{GE}} \mathrm{N} \delta \mathrm{q}_{\mathrm{e}}
$$

The acceleration vector can be written as:

$$
\ddot{\mathrm{X}}=\ddot{\mathrm{X}}_{\mathrm{R}}+\left[(\dot{\Omega}+\Omega \Omega) \mathrm{T}_{\mathrm{IG}}\left[\mathrm{x}_{\mathrm{o}}+\mathrm{T}_{\mathrm{GE}} \mathrm{x}_{\mathrm{e}}+\mathrm{T}_{\mathrm{GE}} \mathrm{Nq}_{\mathrm{e}}\right]\right]+2 \Omega \mathrm{T}_{\mathrm{IG}} \mathrm{T}_{\mathrm{GE}} \mathrm{N} \dot{\mathrm{q}}_{\mathrm{e}}+\mathrm{T}_{\mathrm{IG}} \mathrm{T}_{\mathrm{GE}} \mathrm{N} \ddot{\mathrm{q}}_{\mathrm{e}}
$$


Using the above terms, the virtual work expression in Eq. (1.16) now becomes:

$$
\delta \mathrm{W}=\rho \int_{\mathrm{v}}\left(\begin{array}{l}
\delta \mathrm{q}_{\mathrm{e}}^{\mathrm{T}} \mathrm{N}^{\mathrm{T}} \mathrm{T}_{\mathrm{GE}}^{\mathrm{T}} \mathrm{T}_{\mathrm{IG}}^{\mathrm{T}} \ddot{\mathrm{X}}_{\mathrm{R}}+ \\
\delta \mathrm{q}_{\mathrm{e}}^{\mathrm{T}} \mathrm{N}^{\mathrm{T}} \mathrm{T}_{\mathrm{GE}}^{\mathrm{T}} \mathrm{T}_{\mathrm{IG}}^{\mathrm{T}}(\dot{\Omega}+\Omega \Omega) \mathrm{T}_{\mathrm{IG}} \mathrm{x}_{\mathrm{o}}+ \\
\delta \mathrm{q}_{\mathrm{e}}^{\mathrm{T}} \mathrm{N}^{\mathrm{T}} \mathrm{T}_{\mathrm{GE}}^{\mathrm{T}} \mathrm{T}_{\mathrm{IG}}^{\mathrm{T}}(\dot{\Omega}+\Omega \Omega) \mathrm{T}_{\mathrm{IG}} \mathrm{T}_{\mathrm{GE}} \mathrm{x}_{\mathrm{e}}+ \\
\delta \mathrm{q}_{\mathrm{e}}^{\mathrm{T}} \mathrm{N}^{\mathrm{T}} \mathrm{T}_{\mathrm{GE}}^{\mathrm{T}} \mathrm{T}_{\mathrm{IG}}^{\mathrm{T}}(\dot{\Omega}+\Omega \Omega) \mathrm{T}_{\mathrm{IG}} \mathrm{T}_{\mathrm{GE}} \mathrm{Nq}_{\mathrm{e}}+\mathrm{dV} \\
2 \delta \mathrm{q}_{\mathrm{e}}^{\mathrm{T}} \mathrm{N}^{\mathrm{T}} \mathrm{T}_{\mathrm{GE}}^{\mathrm{T}} \mathrm{T}_{\mathrm{IG}}^{\mathrm{T}} \Omega \mathrm{T}_{\mathrm{IG}} \mathrm{T}_{\mathrm{GE}} \mathrm{N} \dot{\mathrm{q}}_{\mathrm{e}}+ \\
\delta \mathrm{q}_{\mathrm{e}}^{\mathrm{T}} \mathrm{N}^{\mathrm{T}} \mathrm{T}_{\mathrm{GE}}^{\mathrm{T}} \mathrm{T}_{\mathrm{IG}}^{\mathrm{T}} \mathrm{T}_{\mathrm{IG}} \mathrm{T}_{\mathrm{GE}} \mathrm{N} \ddot{\mathrm{q}}_{\mathrm{e}}
\end{array}\right)
$$

From this expression, the element local mass matrix, gyroscopic damping matrix, dynamic stiffness matrix, and the inertial contribution to the force vector are given by

$$
\begin{gathered}
\mathrm{M}_{\mathrm{el}}=\rho \int_{\mathrm{V}}\left(\mathrm{N}^{\mathrm{T}} \mathrm{T}_{\mathrm{GE}}^{\mathrm{T}} \mathrm{T}_{\mathrm{IG}}^{\mathrm{T}} \mathrm{T}_{\mathrm{IG}} \mathrm{T}_{\mathrm{GE}} \mathrm{N}\right) \mathrm{dV} \\
\mathrm{C}_{\mathrm{el}}=2 \rho \int_{\mathrm{V}} \mathrm{N}^{\mathrm{T}} \mathrm{T}_{\mathrm{GE}}^{\mathrm{T}} \mathrm{T}_{\mathrm{IG}}^{\mathrm{T}} \Omega \mathrm{T}_{\mathrm{IG}} \mathrm{T}_{\mathrm{GE}} \mathrm{N} \mathrm{dV} \\
\mathrm{K}_{\mathrm{el}}^{\mathrm{dyn}}=\rho \int_{\mathrm{V}} \mathrm{N}^{\mathrm{T}} \mathrm{T}_{\mathrm{GE}}^{\mathrm{T}} \mathrm{T}_{\mathrm{IG}}^{\mathrm{T}}(\dot{\Omega}+\Omega \Omega) \mathrm{T}_{\mathrm{IG}} \mathrm{T}_{\mathrm{GE}} \mathrm{N} \mathrm{dV} \\
\mathrm{F}_{\mathrm{el}}^{\mathrm{p}}=-\rho \int_{\mathrm{V}}\left(\mathrm{N}^{\mathrm{T}} \mathrm{T}_{\mathrm{GE}}^{\mathrm{T}} \mathrm{T}_{\mathrm{IG}}^{\mathrm{T}} \ddot{X}_{\mathrm{R}}+\mathrm{N}^{\mathrm{T}} \mathrm{T}_{\mathrm{GE}}^{\mathrm{T}} \mathrm{T}_{\mathrm{IG}}^{\mathrm{T}}(\dot{\Omega}+\Omega \Omega) \mathrm{T}_{\mathrm{IG}} \mathrm{x}_{\mathrm{o}}+\mathrm{N}^{\mathrm{T}} \mathrm{T}_{\mathrm{GE}}^{\mathrm{T}} \mathrm{T}_{\mathrm{IG}}^{\mathrm{T}}(\dot{\Omega}+\Omega \Omega) \mathrm{T}_{\mathrm{IG}} \mathrm{T}_{\mathrm{GE}} \mathrm{x}_{\mathrm{e}}\right) \mathrm{dV}
\end{gathered}
$$

These equations are numerically integrated using a 7 point Gauss quadrature [57]. The element mass matrix in Eq. (1.22) is consistent. The damping matrix in Eq. (1.23) is a skew-symmetric matrix arising from Coriolis forces. The stiffness matrix in Eq. (1.24) is a dynamic term representing the coupling effect between the large rigid body motions and the elastic motions. The elastic portion of the stiffness matrix will be discussed subsequently. The force vector in Eq. (1.25) is due to the prescribed rigid body motion. The first term arises from rigid body translational motion. The second and the third terms arise from rigid body angular and centrifugal accelerations. A fourth term in the forcing vector will arise due to aerodynamic loading (discussed later). The key steps involved in the computation of the virtual work due to inertial forces and the computation of the element matrices in the local element frame are highlighted in a flowchart shown in Figure 5.

\section{Element local deformations (co-rotational approach)}

As mentioned above, the static co-rotational formulation of a shell element as described in Refs. [29, 30, 34] is used in this work. While full details of the approach are provided in those references, a brief overview of it is presented here, while extensively quoting from Ref. [29]. Referring to Figure 4, the origin of the undeformed system is chosen at node 1 of the element and the axis $\mathrm{E}_{\mathrm{O}_{1}}$ (i.e., the local $\mathrm{x}$-axis) is chosen as the line joining nodes 1 and 2.

The axis $\mathrm{E}_{\mathrm{O}_{3}}$ (the local z-axis) is the normal to the element mid-plane containing the nodes 1,2 , and 3 . The axis $\mathrm{E}_{\mathrm{O}_{2}}$ (the local y-axis) defines a Cartesian right-handed coordinate system.

The coordinate system denoted by $\mathrm{E}$ is the element co-rotational system defined in a similar fashion but in the current or deformed configuration. The nodal coordinate systems are denoted by $\mathrm{S}_{\mathrm{o}}$ and $\mathrm{S}$ in the undeformed and deformed configurations respectively (shown only for node 2 in Figure 4 for clarity). The orientation of $S_{0}$ is arbitrary and is chosen to be parallel to the global frame in this work. The coordinate system $\mathrm{S}$ in the current configuration is obtained by updating its transformation matrix $\mathrm{T}_{\mathrm{S}}$, which defines the current orientation of the node in the global system. This is done after every iteration using the following expression:

$$
\left(\mathrm{T}_{\mathrm{S}}\right)_{\text {new }}=\overline{\mathrm{T}}\left(\mathrm{T}_{\mathrm{S}}\right)_{\text {old }}
$$


where

$$
\begin{gathered}
\overline{\mathrm{T}}=\mathrm{I}+\frac{\tilde{\omega}_{\mathrm{n}}+0.5 \tilde{\omega}_{\mathrm{n}}^{2}}{1+0.25\left|\omega_{\mathrm{n}}\right|^{2}} \\
\omega_{\mathrm{n}}=\left[\begin{array}{lll}
\bar{\theta}_{\mathrm{X}} & \bar{\theta}_{\mathrm{Y}} & \bar{\theta}_{\mathrm{Z}}
\end{array}\right]^{\mathrm{T}} \\
\left|\omega_{\mathrm{n}}\right|=\sqrt{\bar{\theta}_{\mathrm{X}}^{2}+\bar{\theta}_{\mathrm{Y}}^{2}+\bar{\theta}_{\mathrm{Z}}^{2}} \\
\tilde{\omega}_{\mathrm{n}}=\left[\begin{array}{ccc}
0 & -\bar{\theta}_{\mathrm{Z}} & \bar{\theta}_{\mathrm{Y}} \\
\bar{\theta}_{\mathrm{Z}} & 0 & -\bar{\theta}_{\mathrm{X}} \\
-\bar{\theta}_{\mathrm{Y}} & \bar{\theta}_{\mathrm{X}} & 0
\end{array}\right]
\end{gathered}
$$

The $\bar{\theta}$ quantities are the incremental rotations of triad $\mathrm{S}$ computed in the global coordinate system during the previous iteration.

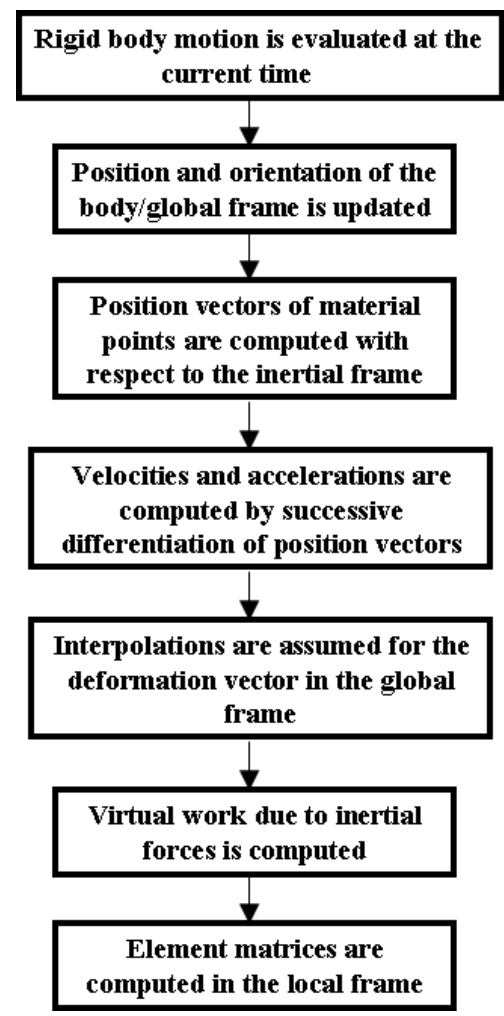

Figure 5. Computation of virtual work due to inertial forces.

Once the nodal coordinate systems in the current configuration are obtained, the next step is the computation of the pure deformations (both displacements and rotations) in the local coordinate system E. Pure nodal displacements at a node " $\mathrm{m}$ " in E may be expressed by the relation:

$$
u_{E}^{m}=\left\{\begin{array}{l}
u_{E_{1}}^{m} \\
u_{E_{2}}^{m} \\
u_{E_{3}}^{m}
\end{array}\right\}=T_{E G}^{C}\left(q_{d g}^{m}+x_{o}^{m}-q_{d g}^{1}-x_{o}^{1}\right)-x_{e}^{m}
$$


where $m=1,2,3 . \mathrm{T}_{\mathrm{EG}}^{\mathrm{C}}$ is a transformation matrix from global frame to the current element frame, $\mathrm{q}_{\mathrm{dg}}^{\mathrm{m}}$ is the displacement vector of a node $\mathrm{m}$ in the global frame, $\mathrm{x}_{\mathrm{o}}^{\mathrm{m}}$ is the position vector of node $\mathrm{m}$ in the undeformed configuration expressed in the global frame. $\mathrm{x}_{\mathrm{o}}^{1}$ is equal to $\mathrm{x}_{\mathrm{o}}$ introduced in Eq. (1.10).

Pure nodal rotations expressed in $\mathrm{E}$ are equal to the components of an anti-symmetric matrix spin tensor defined as:

$$
\Omega_{\mathrm{pn}}=\left[\begin{array}{ccc}
0 & -\theta_{\mathrm{E}_{3}} & \theta_{\mathrm{E}_{2}} \\
\theta_{\mathrm{E}_{3}} & 0 & -\theta_{\mathrm{E}_{1}} \\
-\theta_{\mathrm{E}_{2}} & \theta_{\mathrm{E}_{1}} & 0
\end{array}\right]
$$

This tensor is found by the following expressions:

$$
\begin{gathered}
\Omega_{\mathrm{pn}}=2(\mathrm{~T}-\mathrm{I})(\mathrm{T}+\mathrm{I})^{-1} \\
\mathrm{~T}=\mathrm{T}_{\mathrm{EG}}^{\mathrm{C}} \mathrm{T}_{\mathrm{S}} \mathrm{T}_{\mathrm{GE}}
\end{gathered}
$$

where the matrices $\mathrm{T}_{\mathrm{EG}}^{\mathrm{C}}$ and $\mathrm{T}_{\mathrm{GE}}^{\mathrm{T}}$ transform the components of a vector in the global frame into those in deformed co-rotational and undeformed co-rotational frames respectively. The vector of pure deformations at a node is given by:

$$
\mathrm{d}_{\text {pure }}^{\mathrm{m}}=\left[\begin{array}{llllll}
\mathrm{u}_{\mathrm{E}_{1}}^{\mathrm{m}} & \mathrm{u}_{\mathrm{E}_{2}}^{\mathrm{m}} & \mathrm{u}_{\mathrm{E}_{3}}^{\mathrm{m}} & \theta_{\mathrm{E}_{1}}^{\mathrm{m}} & \theta_{\mathrm{E}_{2}}^{\mathrm{m}} & \theta_{\mathrm{E}_{3}}^{\mathrm{m}}
\end{array}\right]^{\mathrm{T}}
$$

The vector of pure element deformations is obtained by combining the vectors at all three nodes of the element and is given by:

$$
d_{\text {pure }}=\left\{\begin{array}{l}
d_{\text {pure }}^{1} \\
d_{\text {pure }}^{2} \\
d_{\text {pure }}^{3}
\end{array}\right\}
$$

\section{Element stiffness matrix}

A three-node triangular shell element involving an optimal membrane element (OPT) [58] and a discrete Kirchoff triangle (DKT) plate bending element [59] presented in Ref. [29] is used in this work. Unlike many triangular plate elements, a complete quartic polynomial (15 terms) is used to represent the out-of-plate displacement in this element. However, the usual nine degrees of freedom (DOF) (two rotations and a displacement at each node) are supplemented by extra degrees of freedom at the vertices and mid-sides [60]. The constraint of zero transverse shear strain is enforced at selected locations. With these constraints imposed, a nine DOF element is obtained at the end with two rotations and a displacement at each of the element nodes. As a consequence of the process by which the element is derived, the transverse displacement is not explicitly defined in the interior of the element. Hence, the shape functions required to form either the mass matrix or the stress stiffening matrix (discussed later) are not available. This problem may be overcome by borrowing shape functions from other similar elements. Following Ref. [29], for the displacement interpolation, the shape functions corresponding to a BCIZ plate element are used. The stiffness matrix corresponding to the plate bending DOF can be written as [29]:

$$
K_{b}=\int_{\Omega} B_{b}^{T} D^{e} B_{b} d A=2 A \int_{0}^{1} \int_{0}^{1-\zeta_{3}} B_{b}^{T} D^{e} B_{b} d \zeta_{2} d \zeta_{3}
$$

The OPT element is termed 'optimal' because for any arbitrary aspect ratio, its response for in-plane pure bending is exact [29]. Like the DKT element, the OPT element is based on an assumption on strains and so the shape functions 
are borrowed from another triangular membrane element (LST-Ret) with the same degrees of freedom as that of the OPT element. The stiffness matrix corresponding to the membrane DOF are [29]:

$$
\mathrm{K}_{\mathrm{m}}=\frac{1}{\mathrm{~V}} \mathrm{LEL}^{\mathrm{T}}+\frac{3}{4} \beta_{\mathrm{o}} \tilde{\mathrm{T}}_{\theta \mathrm{u}}^{\mathrm{T}} \mathrm{K}_{\theta} \tilde{\mathrm{T}}_{\theta \mathrm{u}}
$$

The DKT and the OPT element stiffness matrices are combined to form the final shell stiffness matrix of the element and further modified to include the membrane-bending coupling effect for laminated composite plates:

$$
K_{e l}^{\text {shell }}=\left[\begin{array}{cc}
K_{m} & \int B_{m}^{T} \cdot B^{e} \cdot B_{b} d A \\
\int B_{b}^{T} \cdot B^{e} \cdot B_{b} d A & K_{b}
\end{array}\right]
$$

More details of the stiffness matrices including the definition of the individual terms are presented in Ref. [29]. The effect of nonlinear stress stiffening is added to the co-rotational formulation by including a geometric stiffness matrix [60]. The expression for stress stiffening is obtained by considering the work done by the membrane forces as they act through displacements associated with small lateral and in-plane deflections. The final expression for the stress stiffening matrix is given by:

$$
\mathrm{K}_{\mathrm{el}}^{\mathrm{ss}}=2 \mathrm{~A} \int_{\Omega} \mathrm{G}^{\mathrm{T}} J_{\mathrm{t}}^{\mathrm{T}}\left[\begin{array}{ccc}
\mathrm{N}_{\mathrm{mf}} & 0_{2 \times 2} & 0_{2 \times 2} \\
0_{2 \times 2} & \mathrm{~N}_{\mathrm{mf}} & 0_{2 \times 2} \\
0_{2 \times 2} & 0_{2 \times 2} & \mathrm{~N}_{\mathrm{mf}}
\end{array}\right] \mathrm{J}_{\mathrm{t}} \mathrm{Gd} \zeta_{2} \mathrm{~d} \zeta_{3}
$$

The sub-matrix $\mathrm{N}_{\mathrm{mf}}$ of size $2 \times 2$ whose components are the membrane forces, is as same as $\tilde{\mathrm{N}}$ defined in Ref.[29]. More details on the derivation of this expression along with a definition of the individual terms are given in Refs.[29, 60]. Once the pure element deformations are computed, the internal force vector is computed using the local element shell and dynamic stiffness matrices (re-arranged according to desired order of degrees of freedom as in Eq. (1.35)) as:

$$
\mathrm{r}_{\mathrm{el}}^{\mathrm{int}}=\left(\mathrm{K}_{\mathrm{el}}^{\text {shell }}+\mathrm{K}_{\mathrm{el}}^{\mathrm{dyn}}\right) \mathrm{d}_{\text {pure }}
$$

Since the pure deformations obtained in Eq. (1.34) may not be really pure, a projector matrix P can be introduced to bring the non-equilibrated internal force vector into equilibrium. More details about the idea of projection are given in Ref. [61]. The local element stiffness matrix computed in Eq. (1.38) and the internal force vector computed in Eq. (1.40) are filtered through the projector matrix as follows:

$$
\begin{aligned}
& \mathrm{K}_{\mathrm{el}}^{\text {shell-p }}=\mathrm{P}^{\mathrm{T}} \mathrm{K}_{\mathrm{el}}^{\text {shell }} \mathrm{P} \\
& \mathrm{r}_{\mathrm{el}}^{\text {int-p }}=\mathrm{P}^{\mathrm{T}} \mathrm{K}_{\mathrm{el}}^{\text {shell }} \mathrm{d}_{\text {pure }}
\end{aligned}
$$

In computing the projection of the internal force vector above, the contribution due to the dynamic stiffness matrix is excluded. At this point, if the membrane forces are expected to be significant, the stress stiffness matrix obtained in Eq. (1.39) should be added to the projected local element stiffness matrix in Eq. (1.41).

Having obtained the stiffness and mass matrices along with the internal force vector in the element frame, they are transformed into the global frame before the assembly process. The transformation of the element local stiffness matrix which includes both the elastic and the dynamic stiffness terms is given as:

$$
\mathrm{K}_{\mathrm{el}-\mathrm{g}}^{\text {shellyn-p }}=\left(\mathrm{T}_{\mathrm{GE}}^{\mathrm{C}-\mathrm{f}}\right)\left(\mathrm{K}_{\mathrm{el}}^{\text {shell-p }}+\mathrm{K}_{\mathrm{el}}^{\mathrm{dyn}}\right)\left(\mathrm{T}_{\mathrm{GE}}^{\mathrm{C}-\mathrm{f}}\right)^{\mathrm{T}}
$$

where the transformation matrix $\mathrm{T}_{\mathrm{GE}}^{\mathrm{C}-\mathrm{f}}$ above is an expanded form of $\mathrm{T}_{\mathrm{GE}}^{\mathrm{C}}$ (which is transpose of $\mathrm{T}_{\mathrm{EG}}^{\mathrm{C}}$ defined earlier) used to accommodate the transformation of all the 18 degrees of freedom of the element. The subscript "el-g" indicates that the corresponding element matrix operates on the global degrees of freedom. Similarly, the element 
mass and the gyroscopic matrices given in Eqs. (1.22) and (1.23) respectively, are transformed into the global frame as follows:

$$
\begin{aligned}
\mathrm{M}_{\mathrm{el}-\mathrm{g}} & =\mathrm{T}_{\mathrm{GE}} \mathrm{M}_{\mathrm{el}} \mathrm{T}_{\mathrm{GE}}^{\mathrm{T}} \\
\mathrm{C}_{\mathrm{el}-\mathrm{g}} & =\mathrm{T}_{\mathrm{GE}} \mathrm{C}_{\mathrm{el}} \mathrm{T}_{\mathrm{GE}}^{\mathrm{T}}
\end{aligned}
$$

Further, the element internal force and the prescribed motion force vectors given in Eqs. (1.42) and (1.25) respectively are transformed to the global frame as:

$$
\begin{gathered}
\mathrm{r}_{\mathrm{el}-\mathrm{g}}^{\mathrm{int}}=\mathrm{T}_{\mathrm{GE}}^{\mathrm{C}-\mathrm{f}} \mathrm{r}_{\mathrm{el}}^{\mathrm{int}-\mathrm{p}} \\
\mathrm{F}_{\mathrm{el}-\mathrm{g}}^{\mathrm{p}}=\mathrm{T}_{\mathrm{GE}}^{\mathrm{f}} \mathrm{F}_{\mathrm{el}}^{\mathrm{p}}
\end{gathered}
$$

The global element mass, stiffness, gyroscopic damping matrices given in Eqs. (1.44), (1.43), (1.45) respectively, and the element global internal force and the prescribed-motion force vectors given in Eqs. (1.46) and (1.47) respectively, are assembled for the entire structure to form global matrices/vectors. The global mass, tangent stiffness, and damping matrices are denoted as $\mathrm{M}, \mathrm{K}_{\mathrm{t}}$, and $\mathrm{C}$ respectively, while the global internal and the total force vectors are denoted as $\mathrm{R}$ and $\mathrm{F}$. The total force vector $\mathrm{F}$ also includes the aerodynamic forces expressed in the global frame that are computed from a CFD analysis (discussed later). Figure 6 highlights the key steps involved in the derivation of the global structural matrices that are discussed above.

\section{Direct Time Integration of the CSD Governing Equations}

The nonlinear structural dynamics finite element governing equations of motion can be written as:

$$
\mathrm{Ma}+\mathrm{Cv}+\mathrm{R}(\mathrm{q})=\mathrm{F}
$$

where $q$ is the nodal degree of freedom vector in the global frame, $v$ and a are the global velocity and acceleration vectors respectively. In this work, the numerical integration of the governing equations was performed using either the Newmark or the generalized- $\alpha$ method [62,63]. Ref. [62] discussed the application of the generalized- $\alpha$ scheme for linear problems. In this work, it is extended to solve the nonlinear equations of motion in a predictor-corrector type of framework similar to the one described for the Newmark method in Ref. [64]. The generalized- $\alpha$ method solves second-order differential equations for a discrete time-step, n, using the standard Newmark relations to update the displacements and velocities:

$$
\begin{aligned}
& \mathrm{q}_{\mathrm{n}+1}=\mathrm{q}_{\mathrm{n}}+\Delta \mathrm{tv}_{\mathrm{n}}+\Delta \mathrm{t}^{2}\left[\left(\frac{1}{2}-\beta\right) \mathrm{a}_{\mathrm{n}}+\beta \mathrm{a}_{\mathrm{n}+1}\right] \\
& \mathrm{v}_{\mathrm{n}+1}=\mathrm{v}_{\mathrm{n}}+\Delta \mathrm{t}\left[(1-\gamma) \mathrm{a}_{\mathrm{n}}+\gamma \mathrm{a}_{\mathrm{n}+1}\right]
\end{aligned}
$$

where the balance equation is given by:

$$
\mathrm{Ma}_{\mathrm{n}+1-\alpha_{\mathrm{m}}}+\mathrm{Cv}_{\mathrm{n}+1-\alpha_{\mathrm{f}}}+\mathrm{R}_{\mathrm{n}+1-\alpha_{\mathrm{f}}}=\mathrm{F}\left(\mathrm{t}_{\mathrm{n}+1-\alpha_{\mathrm{f}}}\right)
$$

and

$$
\begin{aligned}
& a_{n+1-\alpha_{m}}=\left(1-\alpha_{m}\right) a_{n+1}+\alpha_{m} a_{n} \\
& v_{n+1-\alpha_{f}}=\left(1-\alpha_{f}\right) v_{n+1}+\alpha_{f} v_{n} \\
& R_{n+1-\alpha_{f}}=\left(1-\alpha_{f}\right) R_{n+1}+\alpha_{f} R_{n} \\
& F\left(t_{n+1-\alpha_{f}}\right)=\left(1-\alpha_{f}\right) F_{n+1}+\alpha_{f} F_{n}
\end{aligned}
$$




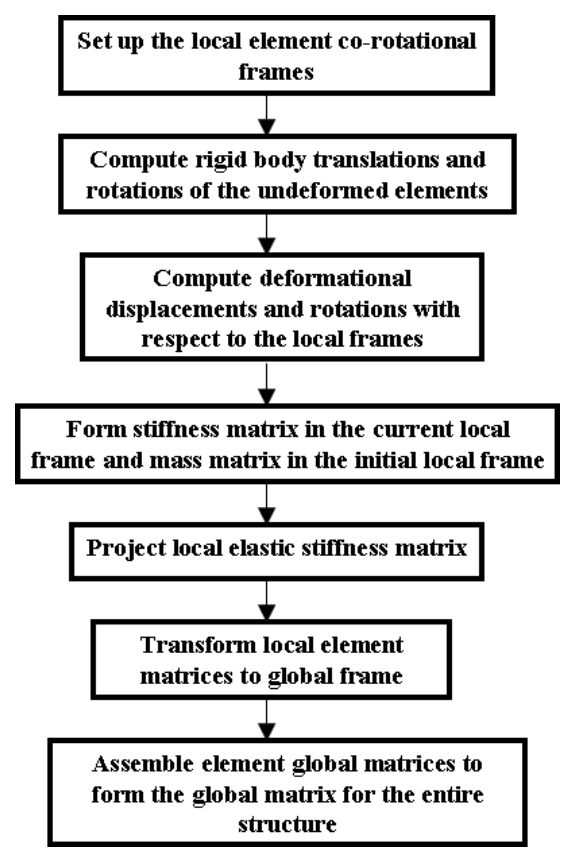

Figure 6. Co-rotational solution process.

Substituting these relations into the balance equation provides:

$$
\operatorname{M}\left[\left(1-\alpha_{m}\right) a_{n+1}+\alpha_{m} a_{n}\right]+C\left[\left(1-\alpha_{f}\right) v_{n+1}+\alpha_{f} v_{n}\right]+\left(1-\alpha_{f}\right) R_{n+1}+\alpha_{f} R_{n}=\left(1-\alpha_{f}\right) F_{n+1}+\alpha_{f} F_{n}
$$

Using the Newmark update relation of displacements Eq. (1.49) the accelerations become:

$$
\begin{gathered}
\mathrm{a}_{\mathrm{n}+1}=\frac{1}{\beta \Delta \mathrm{t}^{2}}\left[\mathrm{q}_{\mathrm{n}+1}-\mathrm{q}_{\mathrm{n}}-\Delta \mathrm{tv}_{\mathrm{n}}-\Delta \mathrm{t}^{2}\left(\frac{1}{2}-\beta\right) \mathrm{a}_{\mathrm{n}}\right] \\
\mathrm{a}_{\mathrm{n}+1}=\frac{1}{\beta \Delta \mathrm{t}^{2}}\left[\delta \mathrm{q}-\Delta \mathrm{tv}_{\mathrm{n}}-\Delta \mathrm{t}^{2}\left(\frac{1}{2}-\beta\right) \mathrm{a}_{\mathrm{n}}\right]
\end{gathered}
$$

Substituting this into the velocity update relation Eq. (1.50):

$$
\mathrm{v}_{\mathrm{n}+1}=\mathrm{v}_{\mathrm{n}}+\Delta \mathrm{t}(1-\gamma) \mathrm{a}_{\mathrm{n}}+\frac{\gamma}{\beta \Delta \mathrm{t}} \delta \mathrm{q}-\frac{\gamma}{\beta} \mathrm{v}_{\mathrm{n}}-\frac{\gamma \Delta \mathrm{t}}{\beta}\left(\frac{1}{2}-\beta\right) \mathrm{a}_{\mathrm{n}}
$$

Substituting the previous two relations Eqs. (1.55), (1.56) in Eq.(1.52), provides:

$$
\begin{gathered}
a_{n+1-\alpha_{m}}=\left(1-\alpha_{m}\right) \frac{1}{\beta \Delta t^{2}}\left[\delta q-\Delta t v_{n}-\Delta t^{2}\left(\frac{1}{2}-\beta\right) a_{n}\right]+\alpha_{m} a_{n} \\
v_{n+1-\alpha_{f}}=\left(1-\alpha_{f}\right)\left[v_{n}+\Delta t(1-\gamma) a_{n}+\frac{\gamma}{\beta \Delta t} \delta q-\frac{\gamma}{\beta} v_{n}-\frac{\gamma \Delta t}{\beta}\left(\frac{1}{2}-\beta\right) a_{n}\right]+\alpha_{f} v_{n}
\end{gathered}
$$

Using the tangent stiffness method [64], the internal forces at time step $n+1$ (i.e., $R_{n+1}$ ) can be written as:

$$
\mathrm{R}_{\mathrm{n}+1}=\mathrm{R}_{\mathrm{n}}+\mathrm{K}_{\mathrm{t}} \delta \mathrm{q}
$$




$$
R_{n+1-\alpha_{f}}=\left(1-\alpha_{f}\right)\left(R_{n}+K_{t} \delta q\right)+\alpha_{f} R_{n}
$$

Substituting the previous equations in the governing equilibrium equation, the balance equation is given by:

$$
\mathrm{K}_{\text {eff }} \delta \mathrm{q}=\mathrm{R}_{\mathrm{h}}
$$

The effective stiffness matrix and the effective load vector are:

$$
\begin{gathered}
\mathrm{K}_{\text {eff }}=\frac{\left(1-\alpha_{\mathrm{m}}\right)}{\beta \Delta \mathrm{t}^{2}} \mathrm{M}+\frac{\left(1-\alpha_{\mathrm{f}}\right) \gamma}{\beta \Delta t} \mathrm{C}+\left(1-\alpha_{\mathrm{f}}\right) \mathrm{K}_{\mathrm{t}} \\
\mathrm{R}_{\mathrm{h}}=\frac{\left(1-\alpha_{\mathrm{m}}\right)}{\beta \Delta \mathrm{t}} \mathrm{M} \mathrm{v}_{\mathrm{n}}+\frac{\left(1-\alpha_{\mathrm{m}}\right)}{\beta}\left(\frac{1}{2}-\beta\right) M \mathrm{a}_{\mathrm{n}}-\alpha_{\mathrm{m}} M \mathrm{a}_{\mathrm{n}}-\mathrm{C}\left(1-\alpha_{\mathrm{f}}\right) \mathrm{v}_{\mathrm{n}}- \\
\ldots-\mathrm{C}\left(1-\alpha_{\mathrm{f}}\right) \Delta \mathrm{t}(1-\gamma) \mathrm{a}_{\mathrm{n}}+\mathrm{C}\left(1-\alpha_{\mathrm{f}}\right) \frac{\gamma}{\beta} \mathrm{v}_{\mathrm{n}}+\mathrm{C}\left(1-\alpha_{\mathrm{f}}\right) \frac{\gamma \Delta \mathrm{t}}{\beta}\left(\frac{1}{2}-\beta\right) \mathrm{a}_{\mathrm{n}}- \\
\ldots \mathrm{C} \alpha_{\mathrm{f}} \mathrm{v}_{\mathrm{n}}-\left(1-\alpha_{\mathrm{f}}\right) \mathrm{R}_{\mathrm{n}}-\alpha_{\mathrm{f}} \mathrm{R}_{\mathrm{n}}+\left(1-\alpha_{\mathrm{f}}\right) \mathrm{F}_{\mathrm{n}+1}+\alpha_{\mathrm{f}} \mathrm{F}_{\mathrm{n}}
\end{gathered}
$$

A step-by-step solution procedure to solve the system of equations using the quantities computed in Eqns. (1.62) and (1.63) is given as follows:

1) Initialize $q_{0}$ and its time derivatives .

2) Select a time-step size $\Delta t$ and a spectral radius parameter $S(0 \leq S \leq 1)$ : this parameter is inversely proportional to the high frequency dissipation.

3) Compute parameters $\alpha_{\mathrm{f}}=-\mathrm{S} /(1+\mathrm{S})$ and $\alpha_{\mathrm{m}}=(1-2 \mathrm{~S}) /(1+\mathrm{S})$.

4) Compute parameters $\gamma=0.5+\alpha_{m}-\alpha_{f}$ and $\beta=0.25\left(1+\alpha_{m}-\alpha_{f}\right)^{2}$.

5) Form the effective stiffness matrix from the individual mass, damping, and tangent stiffness matrices using Eq. (1.62).

6) Form the effective load vector Eq. (1.63).

7) Solve for the displacement increments using $\delta q=\left(K_{\text {eff }}\right)^{-1} R_{h}$.

To improve the solution accuracy and to avoid the development of numerical instabilities, it is generally necessary to employ iterations within each time step in order to maintain equilibrium [64]. The following are the steps to be followed in a typical iteration (j) within the iterative loop.

a. Evaluate the $(\mathrm{j}-1)^{\text {th }}$ approximation to the acceleration, velocities, and displacements using:

$$
\begin{aligned}
\mathrm{a}_{\mathrm{cc}} & =\frac{1-\alpha_{\mathrm{m}}}{\beta \Delta \mathrm{t}^{2}}, \mathrm{a}_{\mathrm{cl}}=\frac{\gamma}{\beta \Delta \mathrm{t}} \\
\mathrm{a}_{\mathrm{c} 2} & =\frac{1}{\beta \Delta \mathrm{t}}, \mathrm{a}_{\mathrm{c} 3}=\frac{1}{2 \beta}-1 \\
\mathrm{a}_{\mathrm{c} 4} & =\frac{\gamma}{\beta}-1, \mathrm{a}_{\mathrm{c} 5}=\frac{\Delta \mathrm{t}}{2}\left(\frac{\gamma}{\beta}-2\right) \\
\mathrm{a}_{\mathrm{n}+1}^{\mathrm{j}-1} & =\mathrm{a}_{\mathrm{co}} \delta \mathrm{q}^{\mathrm{j}-1}-\mathrm{a}_{\mathrm{c} 2} \dot{\mathrm{q}}_{\mathrm{n}}-\mathrm{a}_{\mathrm{c} 3} \ddot{\mathrm{q}}_{\mathrm{n}} \\
\mathrm{v}_{\mathrm{n}+1}^{\mathrm{j}-1} & =\mathrm{a}_{\mathrm{cl}} \delta \mathrm{q}^{\mathrm{j}-1}-\mathrm{a}_{\mathrm{c} 4} \dot{\mathrm{q}}_{\mathrm{n}}-\mathrm{a}_{\mathrm{c} 5} \ddot{\mathrm{g}}_{\mathrm{n}} \\
\mathrm{q}_{\mathrm{n}+1}^{\mathrm{j}-1} & =\mathrm{q}_{\mathrm{n}}+\delta \mathrm{q}^{\mathrm{j}-1}
\end{aligned}
$$

b. Update nodal rotation matrices using the new approximation to the solution q and Eq. (1.26).

c. Evaluate the $(\mathrm{j}-1)^{\text {th }}$ residual force with:

$$
\begin{aligned}
& \Psi_{n+1}^{j-1}=\left(1-\alpha_{f}\right) F\left(t_{n+1}\right)+\alpha_{f} F\left(t_{n}\right)-M\left(1-\alpha_{m}\right) a_{n+1}^{j-1}-M \alpha_{m} a_{n}-C\left(1-\alpha_{f}\right) v_{n+1}^{j-1}- \\
& \ldots C \alpha_{f} v_{n}-\left(1-\alpha_{f}\right) R_{n+1}^{j-1}-\alpha_{f} R_{n}
\end{aligned}
$$


d. Solve for the $\mathrm{j}^{\text {th }}$ corrected displacements using:

$$
\mathrm{K}_{\text {eff }} \Delta \mathrm{q}^{\mathrm{j}}=\psi_{\mathrm{n}+1}^{\mathrm{j}-1}
$$

e. Evaluate the corrected displacement increments with:

$$
\delta q^{j}=\delta q^{j-1}+\Delta q^{j}
$$

f. Check for convergence of the iteration:

$$
\frac{\left|\Delta q^{j}\right|}{\left|q_{t}+\delta q^{j}\right|} \leq \text { tol }
$$

g. If the solution is not converged, return to step (a); if it does, proceed to the next time-step.

For a specific choice of the parameters involved in the generalized- $\alpha$ method, other integration schemes could be derived. For example, if $\alpha_{\mathrm{f}}=0$ and $\alpha_{\mathrm{m}}=0$, the method reduces to the standard Newmark scheme. The primary goal of this method is to provide the user with control over high frequency dissipation while limiting the impact on the low frequency dynamics. In aeroelastic simulations, this method could prove to be very beneficial in dissipating non-physical high frequency oscillations which result due to poor spatial resolution.

\section{Computational Fluid Dynamics Solution (STREAM)}

The continuity equation and u-momentum equation in curvilinear coordinates are written as follows (the $\mathrm{v}$ and w-momentum equations can be written along similar lines):

$$
\begin{aligned}
\frac{\partial(\mathrm{J} \rho)}{\partial \mathrm{t}}+\frac{\partial(\rho \mathrm{U})}{\partial \xi}+\frac{\partial(\rho \mathrm{V})}{\partial \eta} & +\frac{\partial(\rho \mathrm{W})}{\partial \gamma}=0 \\
\frac{\partial(\mathrm{J} \rho \mathrm{u})}{\partial \mathrm{t}}+\frac{\partial(\rho \mathrm{Uu})}{\partial \xi}+\frac{\partial(\rho \mathrm{Vu})}{\partial \eta}+\frac{\partial(\rho \mathrm{Wu})}{\partial \gamma}= & \frac{\partial}{\partial \xi}\left[\frac{\mu}{\mathrm{J}}\left(\mathrm{q}_{11} \mathrm{u}_{\xi}+\mathrm{q}_{12} \mathrm{u}_{\eta}+\mathrm{q}_{13} \mathrm{u}_{\gamma}\right)\right] \\
& +\frac{\partial}{\partial \eta}\left[\frac{\mu}{\mathrm{J}}\left(\mathrm{q}_{21} \mathrm{u}_{\xi}+\mathrm{q}_{22} \mathrm{u}_{\eta}+\mathrm{q}_{23} \mathrm{u}_{\gamma}\right)\right] \\
& +\frac{\partial}{\partial \gamma}\left[\frac{\mu}{\mathrm{J}}\left(\mathrm{q}_{31} \mathrm{u}_{\xi}+\mathrm{q}_{32} \mathrm{u}_{\eta}+\mathrm{q}_{33} \mathrm{u}_{\gamma}\right)\right] \\
& -\left[\frac{\partial}{\partial \xi}\left(\mathrm{f}_{3} \mathrm{p}\right)+\frac{\partial}{\partial \eta}\left(\mathrm{f}_{6} \mathrm{p}\right)+\frac{\partial}{\partial \gamma}\left(\mathrm{f}_{9} \mathrm{p}\right)\right]
\end{aligned}
$$

where $(\xi, \eta, \gamma)$ are time dependent curvilinear coordinates, $\xi=\xi(\mathrm{x}, \mathrm{y}, \mathrm{z}, \mathrm{t})$. Here, $\mathrm{u}$ is the Cartesian velocity component, $\mathrm{p}$ is the pressure, $\mu$ accounts for both laminar and turbulent viscosity. $\mathrm{U}, \mathrm{V}$, and $\mathrm{W}$, are the contravariant velocity components given by:

$$
\begin{aligned}
& \mathrm{U}=\mathrm{f}_{11}(\mathrm{u}-\dot{\mathrm{x}})+\mathrm{f}_{12}(\mathrm{v}-\dot{\mathrm{y}})+\mathrm{f}_{13}(\mathrm{w}-\dot{\mathrm{z}}) \\
& \mathrm{V}=\mathrm{f}_{21}(\mathrm{u}-\dot{\mathrm{x}})+\mathrm{f}_{22}(\mathrm{v}-\dot{\mathrm{y}})+\mathrm{f}_{23}(\mathrm{w}-\dot{\mathrm{z}}) \\
& \mathrm{W}=\mathrm{f}_{31}(\mathrm{u}-\dot{\mathrm{x}})+\mathrm{f}_{32}(\mathrm{v}-\dot{\mathrm{y}})+\mathrm{f}_{33}(\mathrm{w}-\dot{\mathrm{z}})
\end{aligned}
$$

where $\mathrm{f}_{\mathrm{ij}}, \mathrm{q}_{\mathrm{ij}}$ are the metrics of the conversion from Cartesian coordinates to curvilinear coordinates and $\dot{\mathrm{x}}, \dot{\mathrm{y}}$, and $\dot{z}$ are the grid velocities evaluated as follows:

$$
\dot{\mathrm{x}}_{\mathrm{n}+1}=\frac{\mathrm{x}_{\mathrm{n}+1}-\mathrm{x}_{\mathrm{n}}}{\Delta \mathrm{t}}, \dot{\mathrm{y}}_{\mathrm{n}+1}=\frac{\mathrm{y}_{\mathrm{n}+1}-\mathrm{y}_{\mathrm{n}}}{\Delta \mathrm{t}}, \dot{\mathrm{z}}_{\mathrm{n}+1}=\frac{\mathrm{z}_{\mathrm{n}+1}-\mathrm{z}_{\mathrm{n}}}{\Delta \mathrm{t}}
$$


where $\Delta \mathrm{t}$ is the fluid solver time step. The determinant of the transformation matrix between Cartesian and curvilinear coordinates is given by:

$$
\mathrm{J}=\mathrm{x}_{\xi} \mathrm{y}_{\eta} \mathrm{z}_{\zeta}+\mathrm{x}_{\zeta} \mathrm{y}_{\xi} \mathrm{z}_{\eta}+\mathrm{x}_{\eta} \mathrm{y}_{\zeta} \mathrm{z}_{\xi}-\mathrm{x}_{\xi} \mathrm{y}_{\zeta} \mathrm{z}_{\xi}-\mathrm{x}_{\zeta} \mathrm{y}_{\eta} \mathrm{z}_{\xi}-\mathrm{x}_{\eta} \mathrm{y}_{\xi} \mathrm{z}_{\zeta}
$$

A more detailed discussion about the discretization of these equations can be found in Ref. [65]. When performing computations on a fixed grid, the grid velocities are non-existent, though this is not the case while performing computations on a grid that moves with respect to time. In such cases, two major issues need to be considered: 1) kinematic conditions should be enforced at the interface or the moving boundary (i.e., $u=\dot{x}, v=\dot{y}$ and $\mathrm{w}=\dot{\mathrm{z}}$ : these can be imposed as boundary conditions), and 2) the geometric conservation law must be invoked to evaluate the Jacobian values in order to enforce volume conservation. The numerical solution is obtained using a pressure-based algorithm, with combined cartesian and contravariant velocity variables to facilitate strong conservation law formulations and consistent finite volume treatment, as shown above. The convection terms are discretized using a second-order upwind scheme, while the pressure and viscous terms with a second-order central difference scheme.

\section{Results and Discussion}

This section is divided into two subsections. In the first subsection, validation case studies are presented to test the nonlinear static and dynamics analysis capability of UM/NLAMS. In the second subsection, preliminary validation studies are shown for the coupled aeroelasticity framework involving UM/NLAMS and STREAM.

\section{UM/NLAMS (Vacuum Studies)}

\section{Case 1: Cantilever plate subjected to end moments}

This case was originally analyzed by Khosravi et al. [29] and is used as one of the reference test runs to evaluate the geometrically nonlinear static capability of UM/NLAMS. A cantilevered isotropic plate is subjected to uniform applied moments along the edge opposite to the fixed one. The key parameters related to this case are included in Table 3. Figure 7 shows a plot of the normalized vertical displacement at a point on the tip (point "A" in Figure 8) versus the applied moment. The displacement is normalized with respect to the length of the plate (also for all the cases discussed below unless specified otherwise). The plot compares the solution computed in UM/NLAMS with those provided in the reference paper (which also discusses validation with analytical solutions). As seen, there is an excellent match between the two results. The maximum tip deflection obtained in this case is $\sim 0.4 \mathrm{~m}$ which corresponds to $\sim 70 \%$ of the plate length.

Due to the applied moment, the cantilever plate forms a circular arc as shown in Figure 8. In order to compute the solution as a function of the applied load, a load control approach was followed in this work: the maximum load in the analysis was broken into several load steps and applied in increments. For each load increment, nonlinear static equilibrium was sought to compute the corresponding static response. The convergence criterion within each load step loop was chosen as the absolute difference in the Euclidean norm of the entire solution vector computed in any two consecutive Newton-Raphson iterations. For the current case, the tolerance was set to $10^{-3}$.

\section{Case 2: Cantilever plate subjected to an end lateral load}

This case was originally analyzed by Hsiao [66]: an isotropic cantilever plate is subjected to a lateral load at one of its free corners (node "A" of Figure 10). The key parameters related to this case are included in Table 4 . Figure 9 shows the normalized vertical displacement at the tip (node "B" of Figure 10) versus the applied load. As before, the displacement is normalized with respect to the length of the plate. The maximum displacement found in this case was $\sim 57 \%$ of the plate length. Figure 11 shows snapshots of the static wing deformation for three different load steps.

Table 3. Parameters associated with Case 1.

\begin{tabular}{lc|lc}
\hline \hline plate length & $0.6 \mathrm{~m}$ & Poisson's ratio & 0.3 \\
plate width & $0.3 \mathrm{~m}$ & number of finite elements & 512 \\
plate thickness & $0.001 \mathrm{~m}$ & number of load steps & 25 \\
Young's modulus & $196.2 \mathrm{GPa}$ & &
\end{tabular}




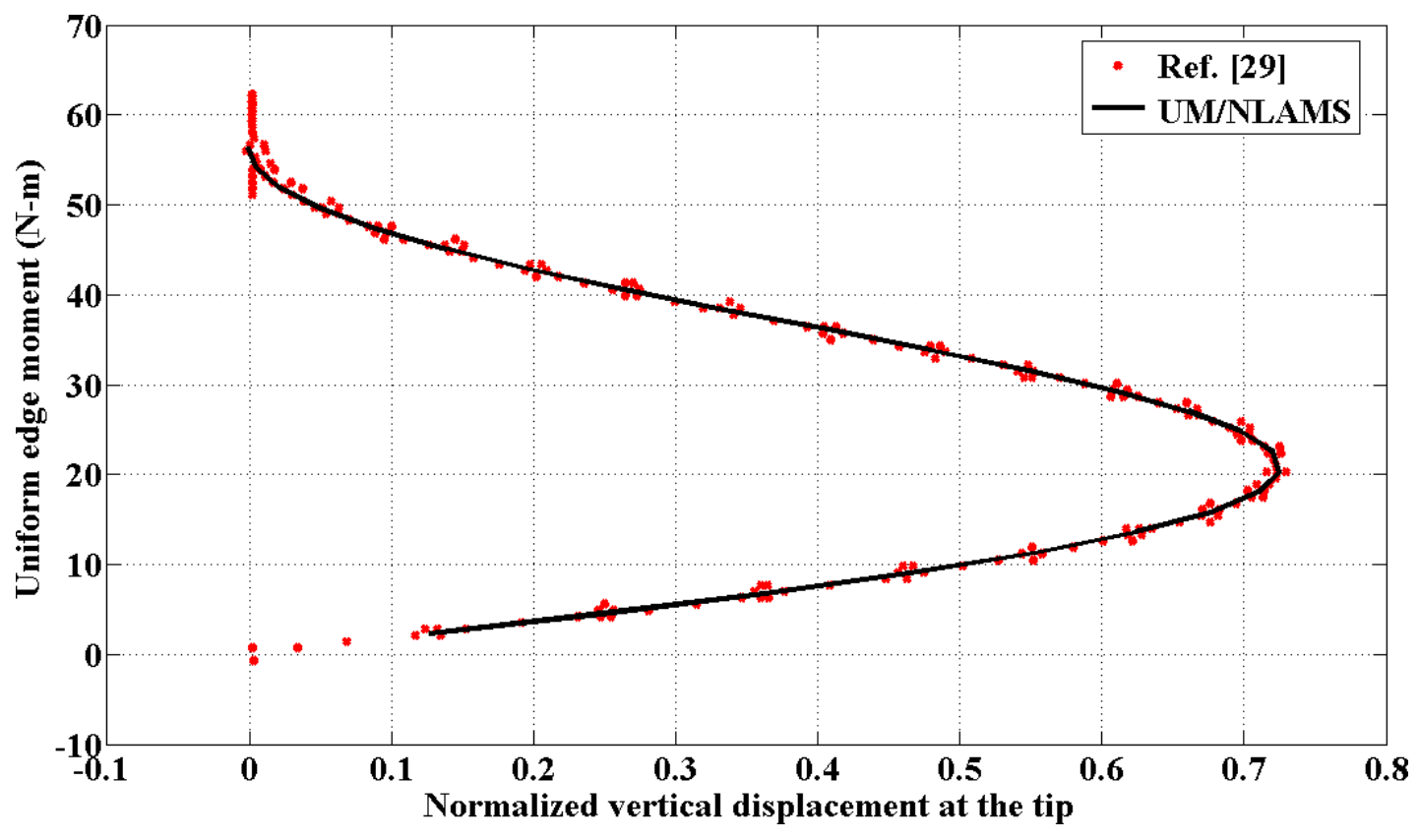

Figure 7. Normalized tip displacement as a function of the applied moment.

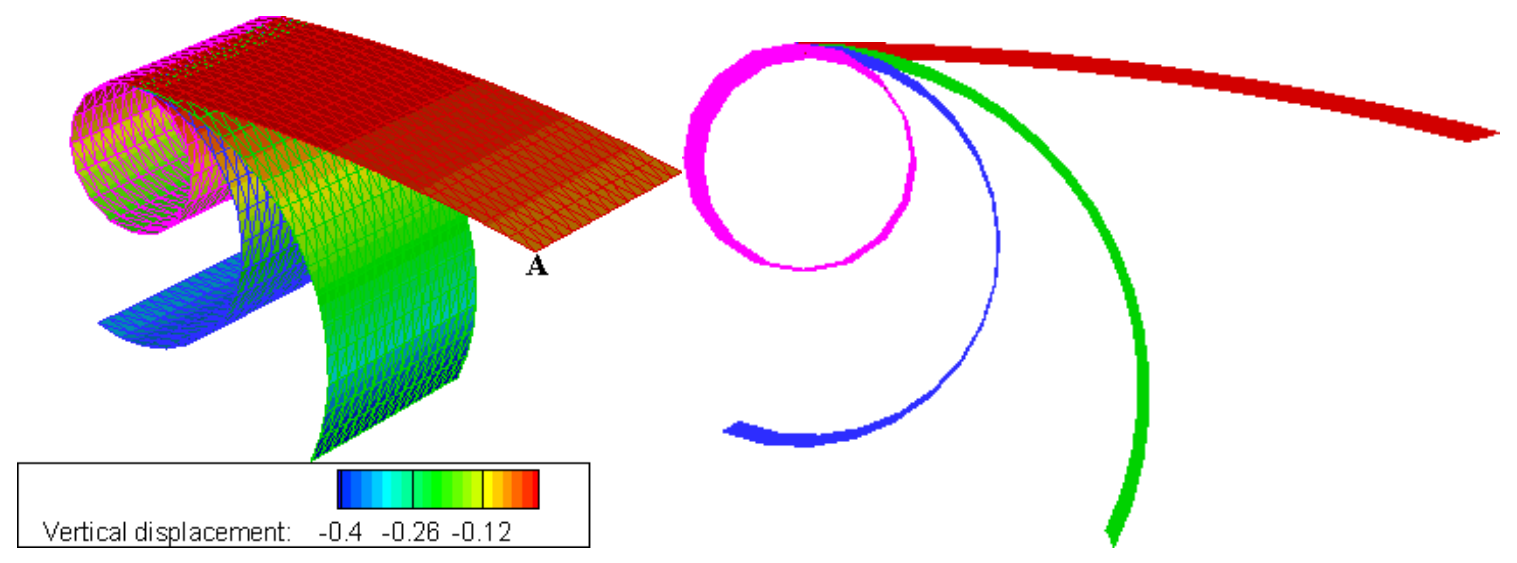

Figure 8. Snapshots of static wing deformation (legend in SI units)

Table 4. Parameters associated with Case 2.

\begin{tabular}{lc|lc}
\hline \hline plate length & $40 \mathrm{~m}$ & Poisson's ratio & 0.3 \\
plate width & $30 \mathrm{~m}$ & number of finite elements & 96 \\
plate thickness & $0.4 \mathrm{~m}$ & number of load steps & 25 \\
Young's modulus & $0.12 \mathrm{GPa}$ & &
\end{tabular}

\section{Case 3: Cantilever plate subjected to an end shear force}

This case was originally analyzed by Khosravi et al. [29]. An isotropic cantilever plate is subjected to shear forces at the three nodes of the tip (nodes "A", "B", and "C" of Figure 12). The maximum load at nodes "A" and "C" is $10 \mathrm{~N}$ whereas at node " $\mathrm{B}$ ", it is $20 \mathrm{~N}$. As in the previous two cases, even here, the maximum load is applied incrementally in several load steps. The key parameters related to this case are included in Table 5. Figure 13 shows the normalized vertical displacement at the tip (node "A" of Figure 12) versus the applied load. The maximum displacement found in this case was approximately $68 \%$ of the plate length. The agreement is very good up to $60 \%$ deformation, after which UM/NLAMS has difficulties to converge within the maximum number of subiterations (200) within a load step. This presents itself as a softer behavior than Ref. [29]. The cause for that is unknown and requires further investigation. 
Table 5. Parameters associated with Case 3.

\begin{tabular}{lc|lc}
\hline \hline plate length & $0.1 \mathrm{~m}$ & Poisson's ratio & 0. \\
plate width & $0.01 \mathrm{~m}$ & number of finite elements & 128 \\
plate thickness & $0.001 \mathrm{~m}$ & number of load steps & 25 \\
Young's modulus & $117.72 \mathrm{GPa}$ & &
\end{tabular}

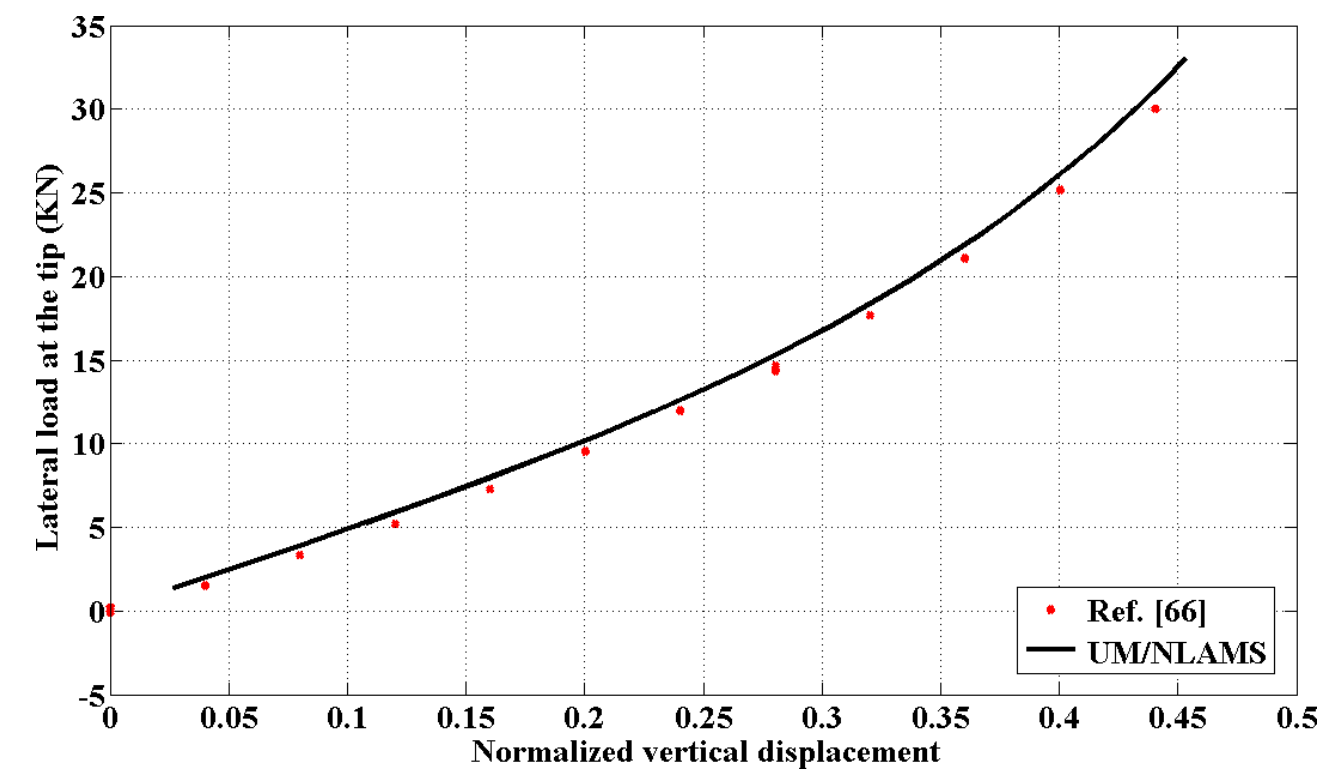

Figure 9. Normalized tip displacement as a function of applied tip load

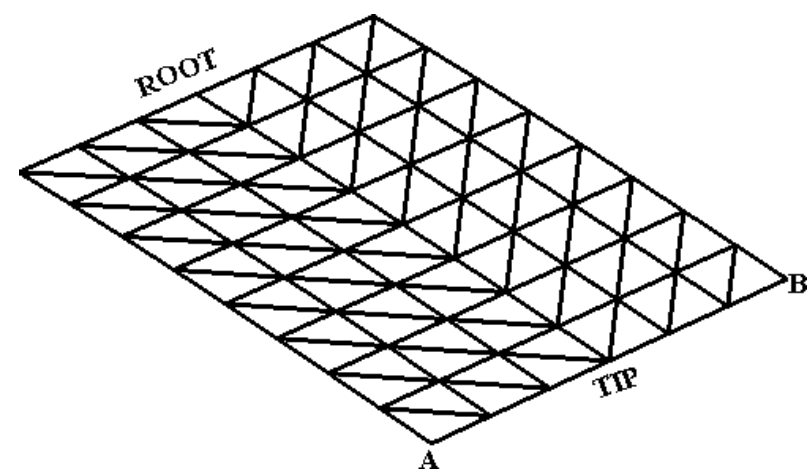

Figure 10. Finite element mesh configuration for the plate in Case 2
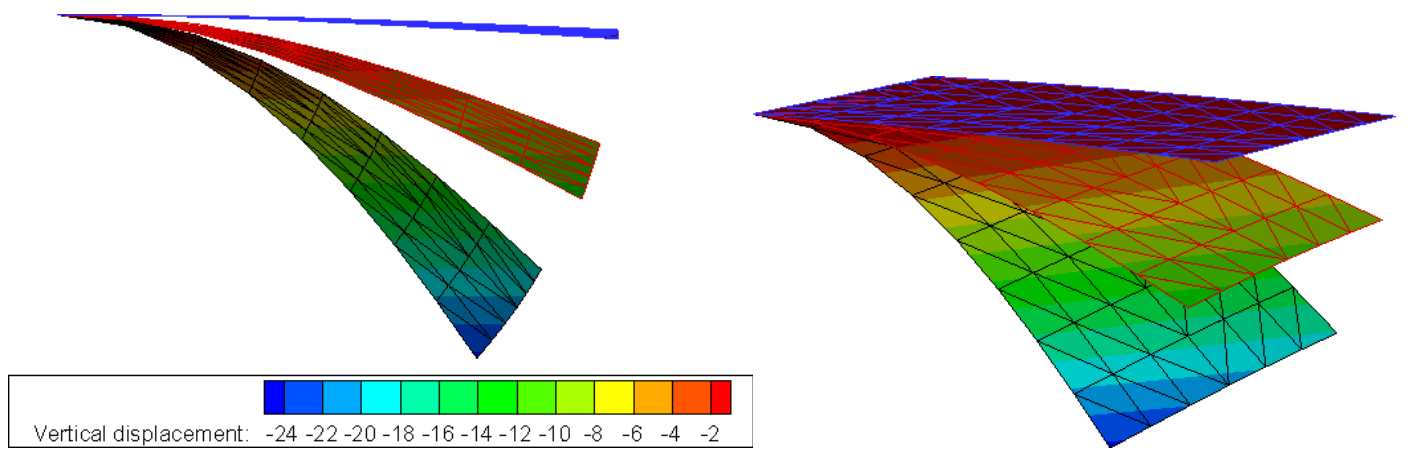

Figure 11. Snapshots of wing deformation (legend in SI units) 


\section{Case 4: Cantilevered rectangular plate in single degree- of- freedom flap rotation}

A rectangular aluminum wing shown in Figure 14 was prescribed with a single degree-of-freedom large amplitude flap rotation about an axis running through the chord. In the figure, the square block at the wing root is constrained in all degrees of freedom, and the rotation was prescribed as a " 1 -cos" variation. This enabled the simulation to start from zero initial displacement and velocity, obviating the need for a special starting procedure as would have been the case if a sine variation was prescribed. The key parameters related to this case are included in Table 6. Figure 15, Figure 16, and Figure 17 show the normalized vertical displacement at the tip (point "A" in Figure 14) as a function of non-dimensional time (time normalized with respect to the period of the flap rotation) for three different flapping frequencies: $5 \mathrm{~Hz}, 10 \mathrm{~Hz}$, and $30 \mathrm{~Hz}$, respectively. These results are compared to those obtained from the commercial finite element solver MSC.Marc. The bilinear thin-triangular shell element no.138 is used to discretize the wing in MSC.Marc (also for all the cases discussed below). The time-integration schemes used are the nondissipative form of the Newmark and the generalized- $\alpha$ methods. The former was used in the $5 \mathrm{~Hz}$ and the $10 \mathrm{~Hz}$ cases whereas the latter in the $30 \mathrm{~Hz}$ case with a spectral radius value set to 0.4 . The time-step size used in the $5 \mathrm{~Hz}$ and $10 \mathrm{~Hz}$ cases was $1.5 \times 10^{-4} \mathrm{~s}$ and in the $30 \mathrm{~Hz}$ case was $10^{-5} \mathrm{~s}$. The convergence criterion for the Newton-Raphson convergence loop is a check on the absolute difference in the Euclidean norm of the entire solution vector computed in any two consecutive iterations, set to $10^{-4}$ in the three cases considered here.

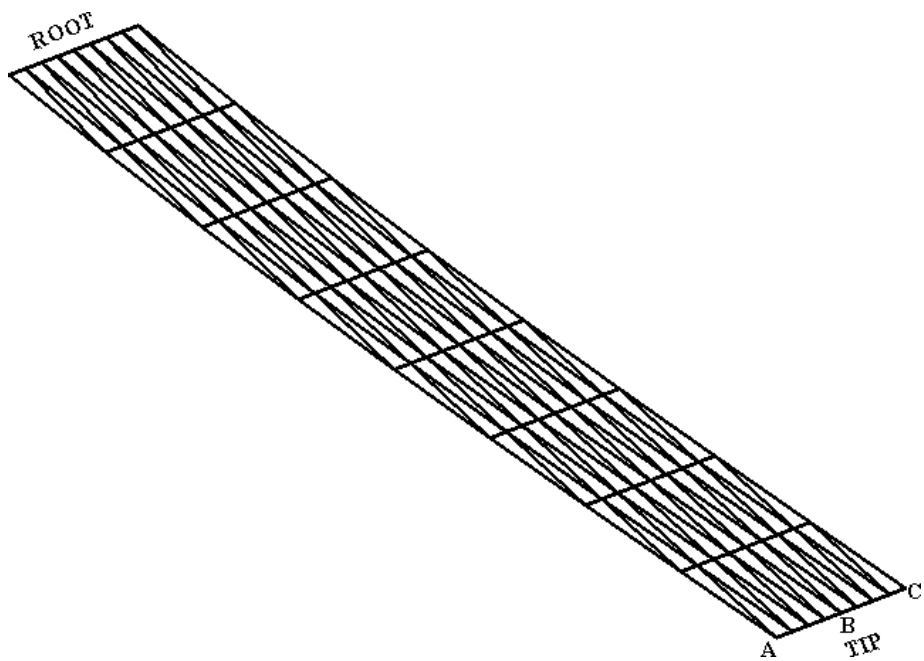

Figure 12. Finite element mesh configuration for the plate in Case 3

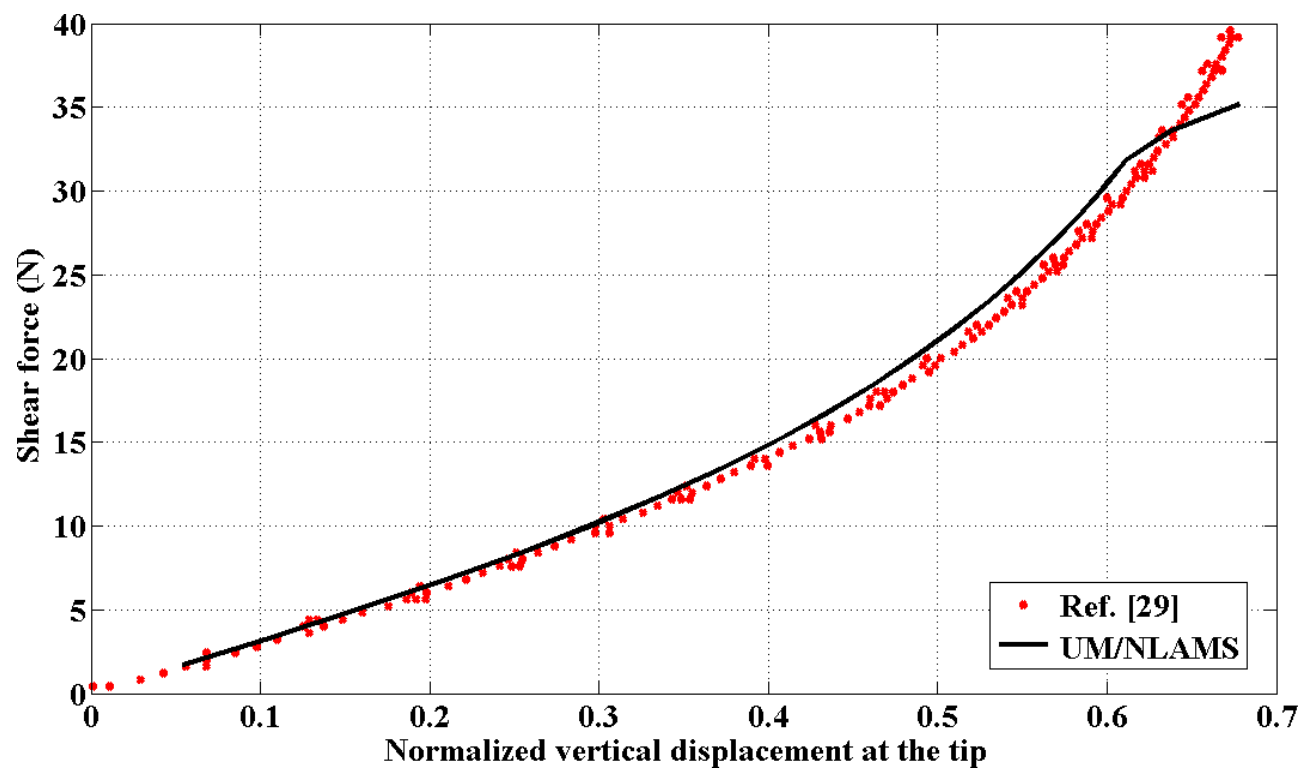

Figure 13. Normalized tip displacement as a function of applied load 
As seen from the results in Figs. 15-17, the agreement between UM/NLAMS and MSC.Marc for lower frequencies is very good. There are noticeable discrepancies in the highest frequency $(30 \mathrm{~Hz})$ response, which is presumably due to the stronger geometric nonlinearities, as well as the increased effect of the transient terms in Eq. (1.48). The exact cause for the discrepancies will require further investigation. Due to these reasons, for the aeroelastic response studies in this work, only the lower frequencies up to $10 \mathrm{~Hz}$ are considered.

Table 6. Parameters associated with Case 4.

\begin{tabular}{lc|lc}
\hline \hline plate length & $80 \mathrm{~mm}$ & prescribed flap rotation profile & $1-\cos$ \\
plate width & $27 \mathrm{~mm}$ & flapping frequency & 5,10, and $30 \mathrm{~Hz}$ \\
plate thickness & $2 \mathrm{~mm}$ & flapping amplitude & $17 \mathrm{deg}$ \\
Young's modulus & $70 \mathrm{GPa}$ & time-step sizes & $1.5 \times 10^{-4} \mathrm{~s}$ and $10^{-5} \mathrm{~s}$ \\
Poisson's ratio & 0.3 & number of finite elements & 512 \\
material density & $2700 \mathrm{~kg} / \mathrm{m}^{3}$ & &
\end{tabular}

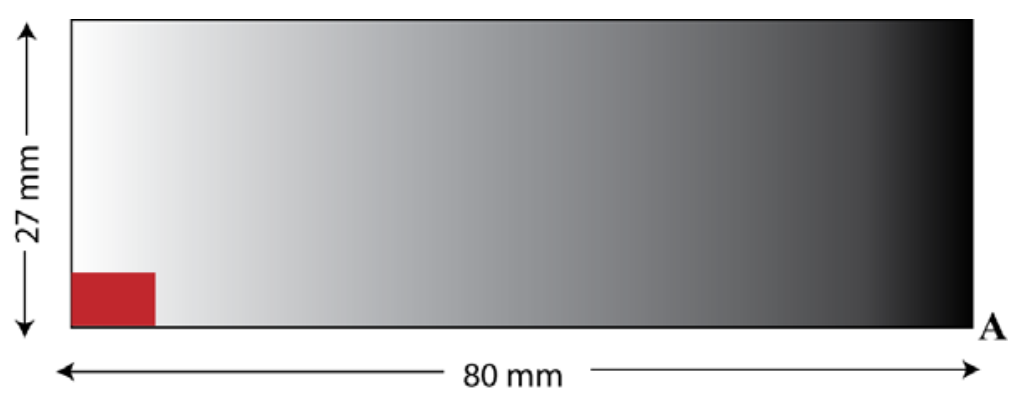

Red color indicates the region ( $5 \mathrm{~mm} \times 5 \mathrm{~mm}$ ) on the wing that is in contact with the flapping mechanism

Figure 14. Rectangular flat plate flapping wing configuration.

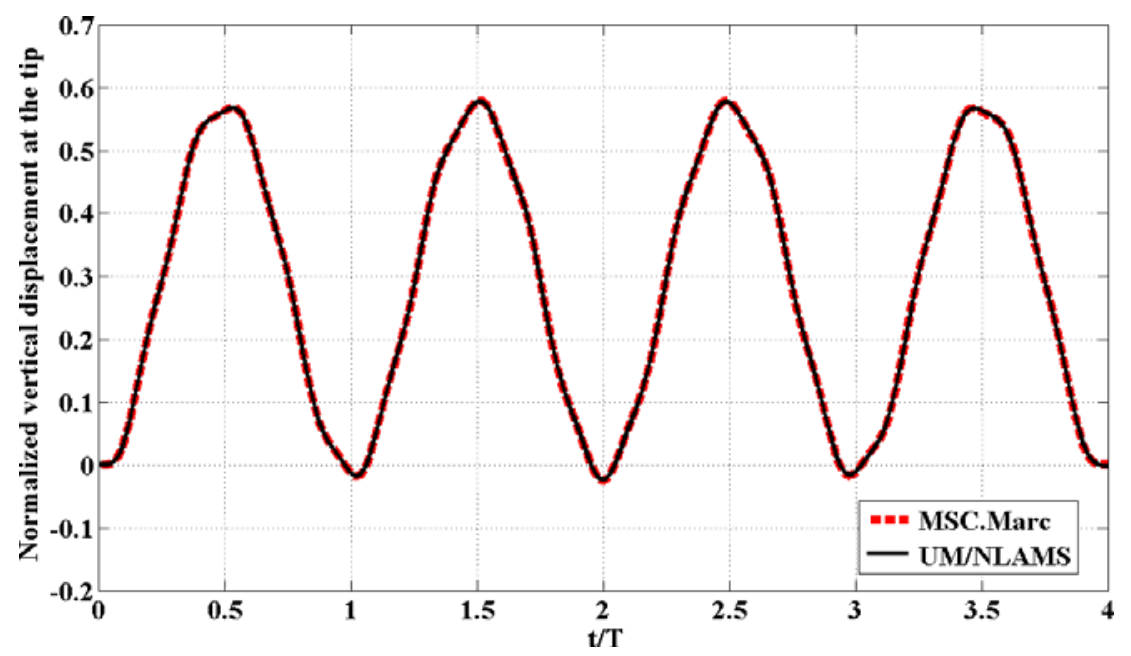

Figure 15. Rectangular plate response due to flapping excitation $(5 \mathrm{~Hz})$. 


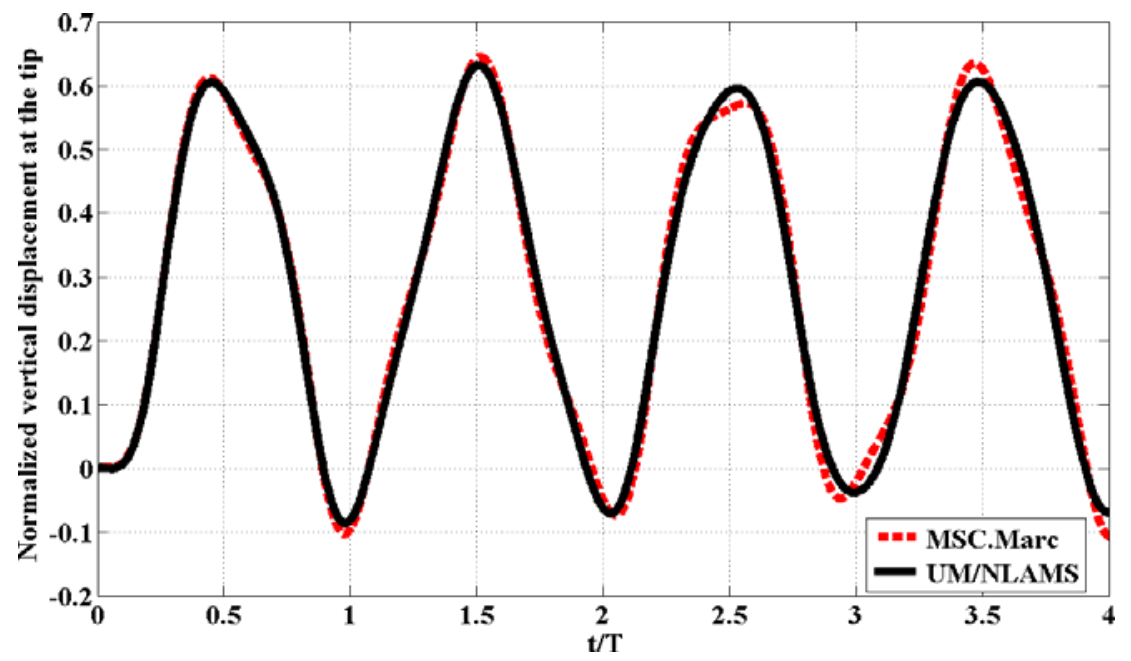

Figure 16. Rectangular plate response due to flapping excitation (10 Hz).

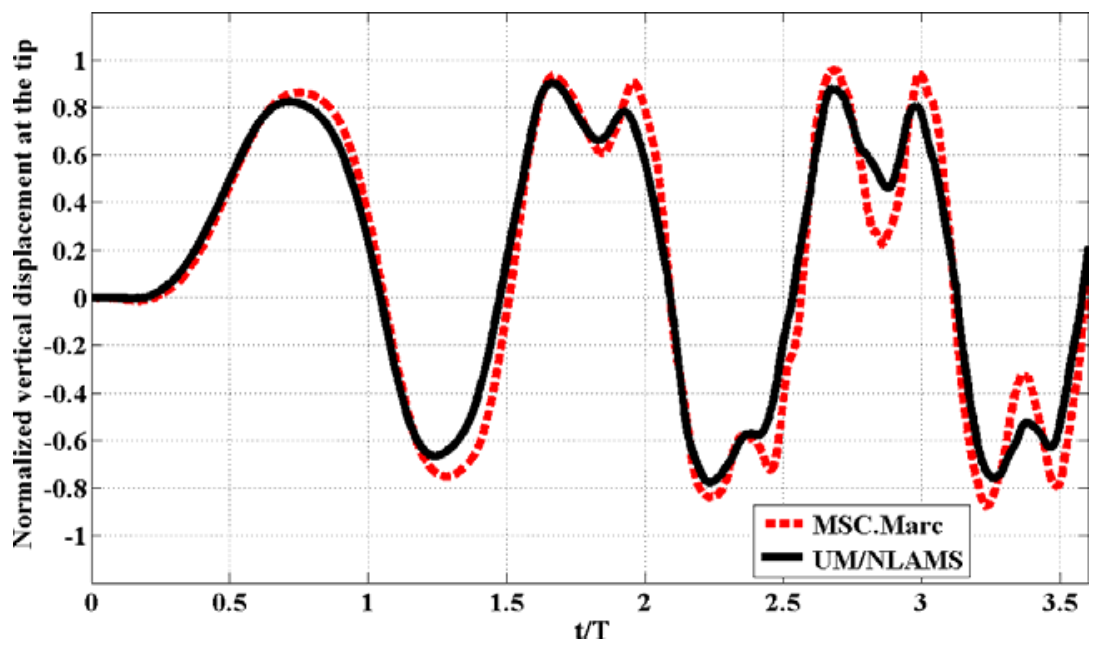

Figure 17. Rectangular plate response due to flapping excitation $(30 \mathrm{~Hz})$.

\section{Case 5: A rectangular wing with prescribed pure plunge motion}

A cantilever steel plate is prescribed with a pure plunge motion at the root. The key parameters related to this case are included in Table 7. Figure 18 shows the normalized vertical displacement at the tip versus the normalized time, with a comparison between UM/NLAMS and the commercial finite element solver MSC.Marc. The displacements and time are normalized with respect to the plunge amplitude and the period of plunge respectively. The time integration method used is the Newmark scheme. As can be seen, there is an excellent match between the results computed in both the codes.

\section{UM/NLAMS and STREAM Coupled Code (Preliminary Aeroelastic Validation)}

\section{Case 6: Aeroelastic response for a rectangular wing prescribed with pure single DOF flap rotation}

The aeroelastic response was computed for the rectangular wing (Figure 14) flapping in incompressible, viscous flow under hovering conditions at $10 \mathrm{~Hz}$. For this case, the key parameters include those in Table 6 that are related to the $10 \mathrm{~Hz}$ case and the ones included in Table 8. The Reynolds number included in the table is based on the following definition:

$$
\mathrm{Re}_{\text {hover }}=\frac{\Phi f \mathrm{R}^{2}}{\mathrm{v}}\left(\frac{4}{\mathrm{~A}_{\mathrm{r}}}\right)
$$


where $\Phi$ is the wing beat amplitude in radians, $\mathrm{f}$ is the flapping frequency in $\mathrm{Hz}, \mathrm{R}$ is the wing length (half wing span), $v$ is the kinematic viscosity of the fluid, $A_{r}$ is the aspect ratio of the wing defined as:

$$
A_{r}=\frac{(2 R)^{2}}{S}
$$

where $\mathrm{S}$ is the planform area defined as the product of the wing span (2R) and the mean chord. The reduced frequency is defined as:

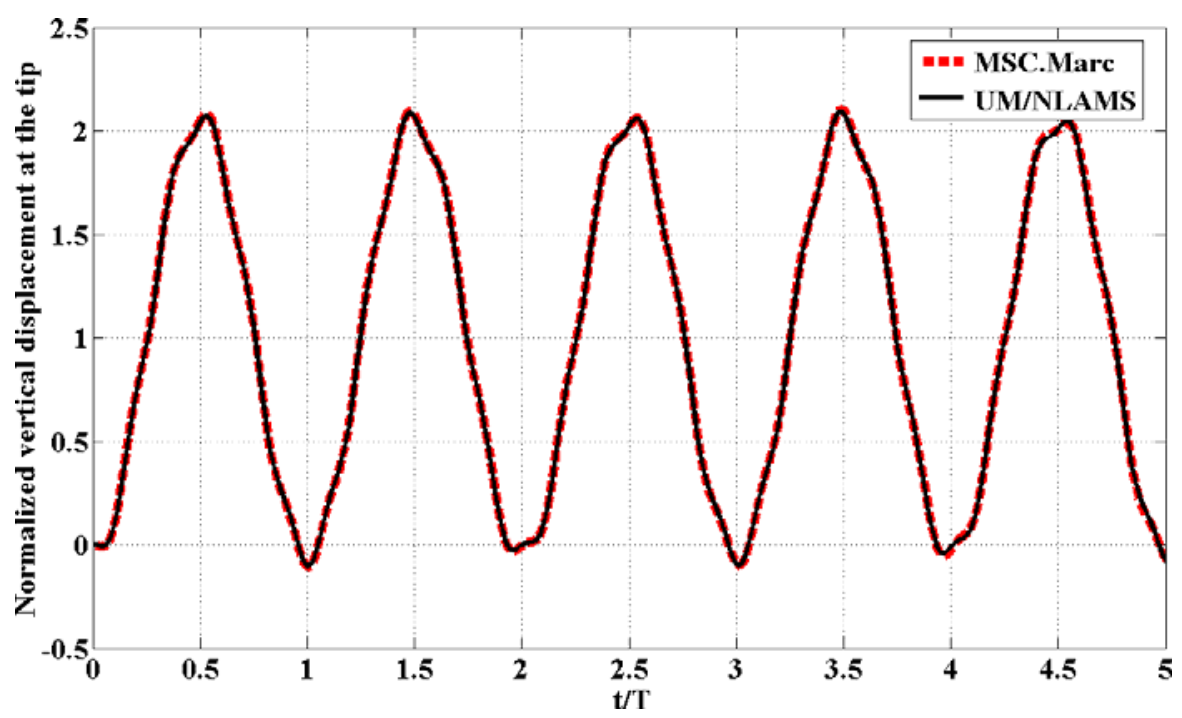

Figure 18. Normalized tip displacement as a function of time.

Table 7. Parameters associated with Case 5.

\begin{tabular}{lc|lc}
\hline \hline plate length & $0.3 \mathrm{~m}$ & prescribed plunge profile & 1-cos \\
plate width & $0.1 \mathrm{~m}$ & plunge frequency & $1.78 \mathrm{~Hz}$ \\
plate thickness & $0.001 \mathrm{~m}$ & plunge amplitude & $0.0175 \mathrm{~m}$ \\
Young's modulus & $210 \mathrm{GPa}$ & time-step size & $10^{-3} \mathrm{~s}$ \\
Poisson's ratio & 0.3 & number of finite elements & 1150 \\
naterial density & $7800 \mathrm{~kg} / \mathrm{m}^{3}$ & &
\end{tabular}

$$
\mathrm{k}=\frac{\pi}{\Phi \mathrm{A}_{\mathrm{r}}}
$$

A structured multi-block H-H type grid around a flat-plate rectangular wing of aspect ratio 5.93 was used for the CFD simulations. The total number of grid points is 0.6 million with close to 300 points on the wing surface. The CFD grid configuration including the boundary conditions is shown in Figure 19. The boundaries on all sides of the wing/wall are 18 chord lengths away from the wing.

Figure 20 shows the variation of displacement at the tip (point " $A$ " in Figure 14) versus non-dimensional time computed in the coupled codes involving UM/NLAMS and MSC.Marc and measured in the experiment. The experimental data was obtained at the University of Florida and the experimental setup used for it is similar to what is described in Ref. [67]. As seen from the figure, there is an overall good agreement between the coupled codes and the experiment. Some noticeable discrepancy in the amplitude will be investigated in greater detail in a future effort, once more experimental data will become available.

Table 8. Parameters associated with Case 6.

\begin{tabular}{lc|lc}
\hline \hline flow velocity & $0 \mathrm{~m} / \mathrm{s}$ & air density & $1.2 \mathrm{~kg} / \mathrm{m}^{3}$ \\
chord-based Reynolds number & 30.8 & MSC.Marc coupling scheme & explicit \\
reduced frequency & 0.89 & UM/NLAMS coupling scheme & implicit
\end{tabular}




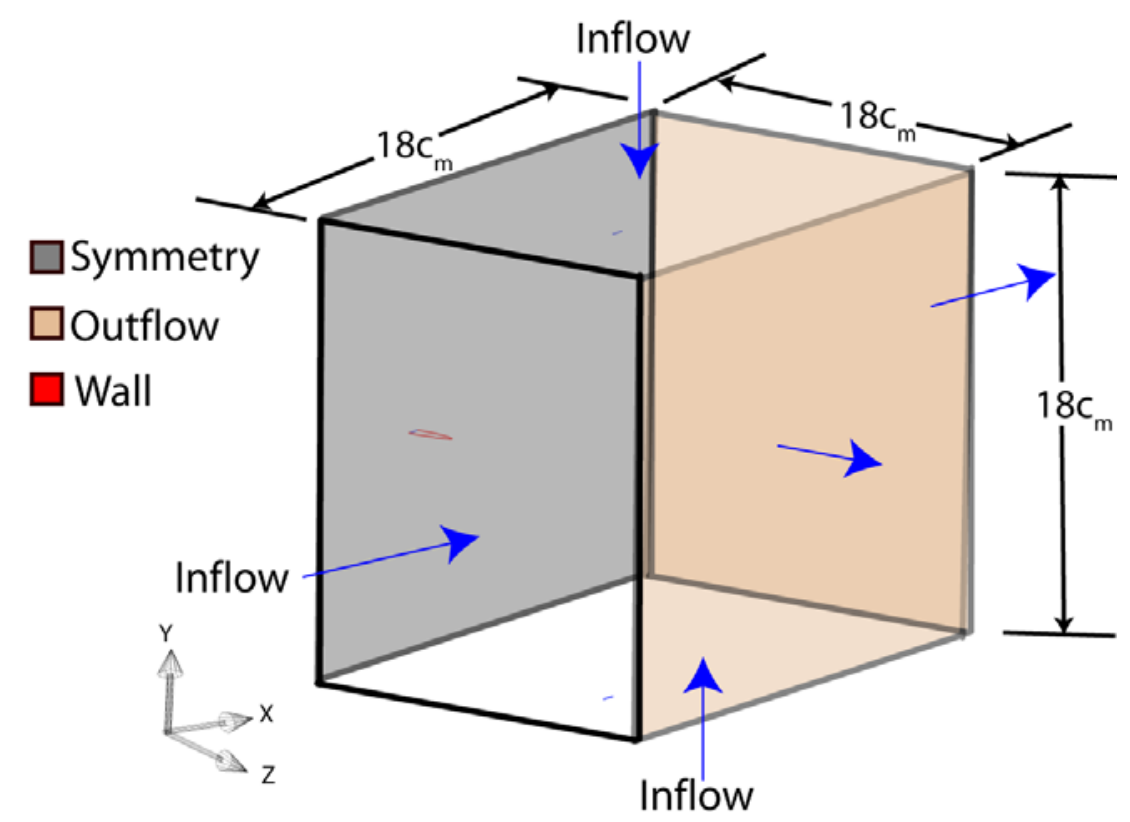

Figure 19. CFD computational model setup for the flapping rectangular wing.

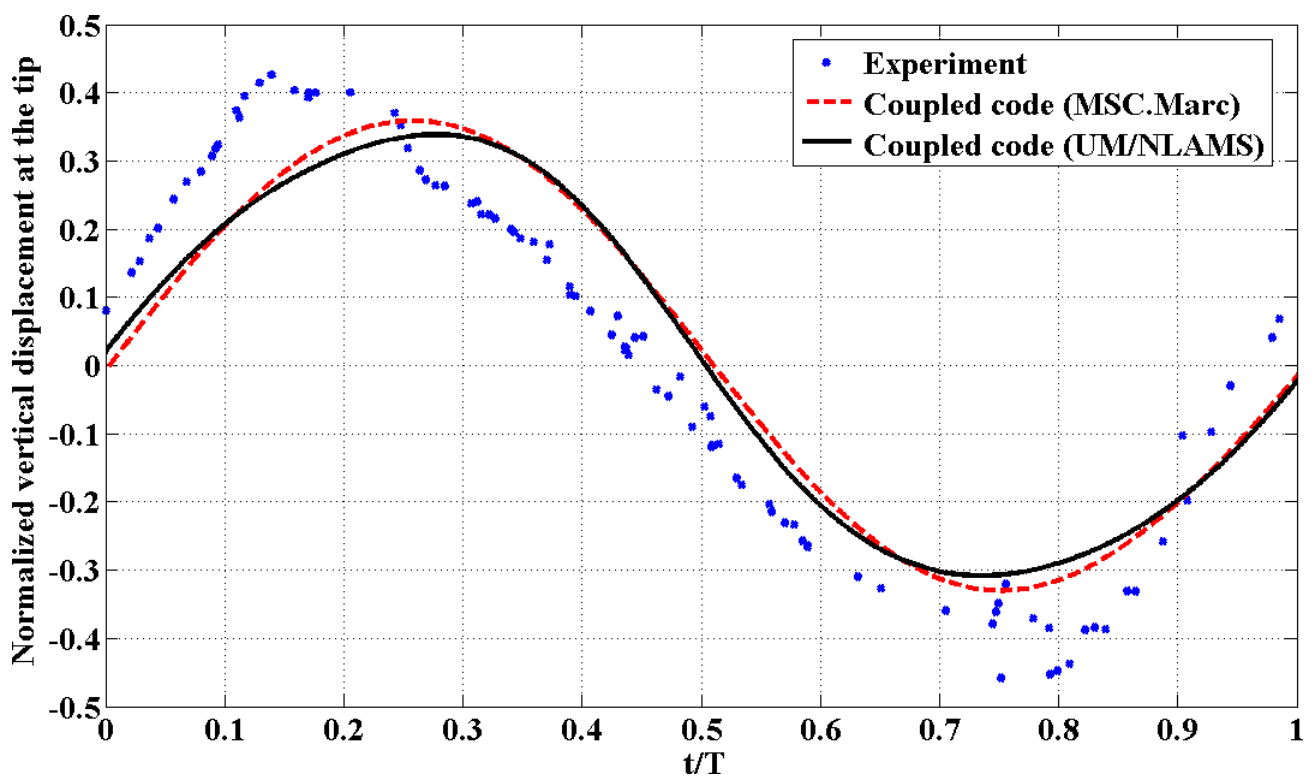

Figure 20. Aeroelastic response of a rectangular wing under pure single DOF flap rotation.

\section{Case 7: Aeroelastic response of a flexible rectangular wing prescribed with pure plunge motion}

Aeroelastic results were obtained for a three-dimensional rectangular wing with NACA0012 uniform cross section (stiffened with a thin sheet of steel insert) oscillating in water under a pure heaving motion in forward flight. Water tunnel studies have been performed by Heathcote et al. [68] to study the effect of spanwise flexibility on the thrust, lift, and propulsive efficiency on this configuration. Later, this wing was simulated using a computational framework involving UM/NLABS, MSC.Marc, and STREAM by the authors [10]. It is again simulated here with the new computational solution involving UM/NLAMS and STREAM. Details of the experimental apparatus and computational setup are furnished in those references. The key parameters related to this case are included in Table 9. The chord-based Reynolds number in the forward flight case is defined as:

$$
\mathrm{Re}_{\mathrm{ff}}=\frac{\mathrm{Uc}_{\mathrm{m}}}{\mathrm{v}}
$$


where $\mathrm{U}$ is the free stream velocity, $\mathrm{c}_{\mathrm{m}}$ is the mean chord.

Table 9. Parameters associated with Case 7

\begin{tabular}{lc|lc}
\hline \hline wing length & $0.3 \mathrm{~m}$ & chord-based Reynolds number & $3 \times 10^{4}$ \\
wing chord & $0.1 \mathrm{~m}$ & reduced frequency & 1.82 \\
structural thickness & $10^{-3} \mathrm{~m}$ & Strouhal number & 0.32 \\
Young's modulus of steel & $210 \mathrm{GPa}$ & prescribed plunge profile & $1-\mathrm{cos}$ \\
Poisson's ratio & 0.3 & plunge frequency & $1.78 \mathrm{~Hz}$ \\
material density of steel & $7800 \mathrm{~kg} / \mathrm{m}^{3}$ & plunge amplitude & $0.0175 \mathrm{~m}$ \\
water density & $1000 \mathrm{~kg} / \mathrm{m}^{3}$ & time-step size & $10^{-3} \mathrm{~s}$ \\
inflow velocity & $0.3 \mathrm{~m} / \mathrm{s}$ & number of finite elements & 1150
\end{tabular}

Two different numerical integration schemes were used to compute the structural response: the Newmark and the generalized- $\alpha$ methods. Further, two different convergence criteria were used in the computations for the implicit convergence within a coupled time-step: 1) a check on the Euclidean norm of the entire solution vector computed in two consecutive fluid-structure subiterations, and 2) a check on the absolute difference of vertical displacement at a tip node in two consecutive fluid-structure subiterations. Figure 21 shows the mean lift coefficient on the wing computed using the Newmark method independently considering both the convergence criteria. As seen in the figure, though expected, it is interesting to see that high frequency oscillations (of approximately $500 \mathrm{~Hz}$ ) are seen in the response computed using the convergence criterion just based on the tip displacement (Newmark-C1). However, these are not seen in the case where a convergence criterion based on the entire solution vector was used (Newmark$\mathrm{C} 2$ ). This is an example of a case in which the smoothness of the aeroelastic response has a dependence on the chosen convergence criterion. Figure 22 shows the normalized vertical displacement (with respect to the amplitude of plunge) at a point on the wing tip versus dimensionless time. As seen in the figure, there is a very good correlation between the response computed in UM/NLAMS, MSC.Marc, and the experiment.

\section{Case 8: Aeroelastic response of a highly flexible rectangular wing prescribed with pure plunge motion}

As mentioned previously, the new aeroelasticity framework involving UM/NLAMS and STREAM has implicit aeroelastic coupling capability which will enable iteration between the flow and the structural solvers more than once per coupled time-step, thereby making the solution more accurate and possibly stable wherever the physics permit. Figure 23 shows the aeroelastic lift coefficient response of a highly flexible rectangular wing prescribed with pure plunge, computed in both the coupled codes involving UM/NLAMS and MSC.Marc. All the parameters for this wing configuration are the same as those of the wing in Case 7 except that the stiffener is made out of aluminium in this case. The time integration scheme used in this case is the Newmark method. While the response computed using the coupled code involving UM/NLAMS is stable, the one in the case of MSC.Marc diverges within the first few coupled time-steps. This behavior persists even for prohibitively small time-steps, e.g., $10^{-5} \mathrm{~s}(5750$ steps per period).

Figure 24 shows the error norm within the first coupled time-step as a function of the fluid-structure subiteration number as computed in the implicit aeroelastic code involving UM/NLAMS. As can be seen, in order to achieve convergence in the first time-step, approximately 30 subiterations were needed for error less than $10^{-6}$. The absence of the fluid-structure subiteration scheme in the coupled code involving MSC.Marc explains why the response is unstable. Since the coupling in that case is controlled by MSC.Marc, there is no correct option for an implicit coupling of the code for aeroelastic analysis.

\section{Concluding Remarks}

A computational aeroelasticity framework suitable for simulating shell-like flapping wings is presented. The structural dynamics model is based on a co-rotational formulation used in conjunction with a flexible multi-body type formulation. The structural dynamics equations of motions are integrated with the generalized- $\alpha$ method (allowing the classic Newmark as a sub-case of it). A Navier-Stokes flow solver that employs a well tested pressurebased algorithm is used to compute the flow. The structural and the fluid dynamic solvers are coupled in a partitioned fashion enabling iteration between them within each coupled time step. Validation studies for both the structural and the aeroelastic solvers are presented for several wing configurations. The computed results were correlated with available reference data and an overall agreement was obtained in all the cases studied. Most 
importantly, the need to use fluid-structure subiterations (implicit aeroelastic coupling) was discussed with an example problem. The new aeroelasticity framework allows for the study of wings with complex planform geometry and material distribution under complex flapping kinematics. Future work will address the combined plunge/pitch excitation of flapping wings in both water and air.

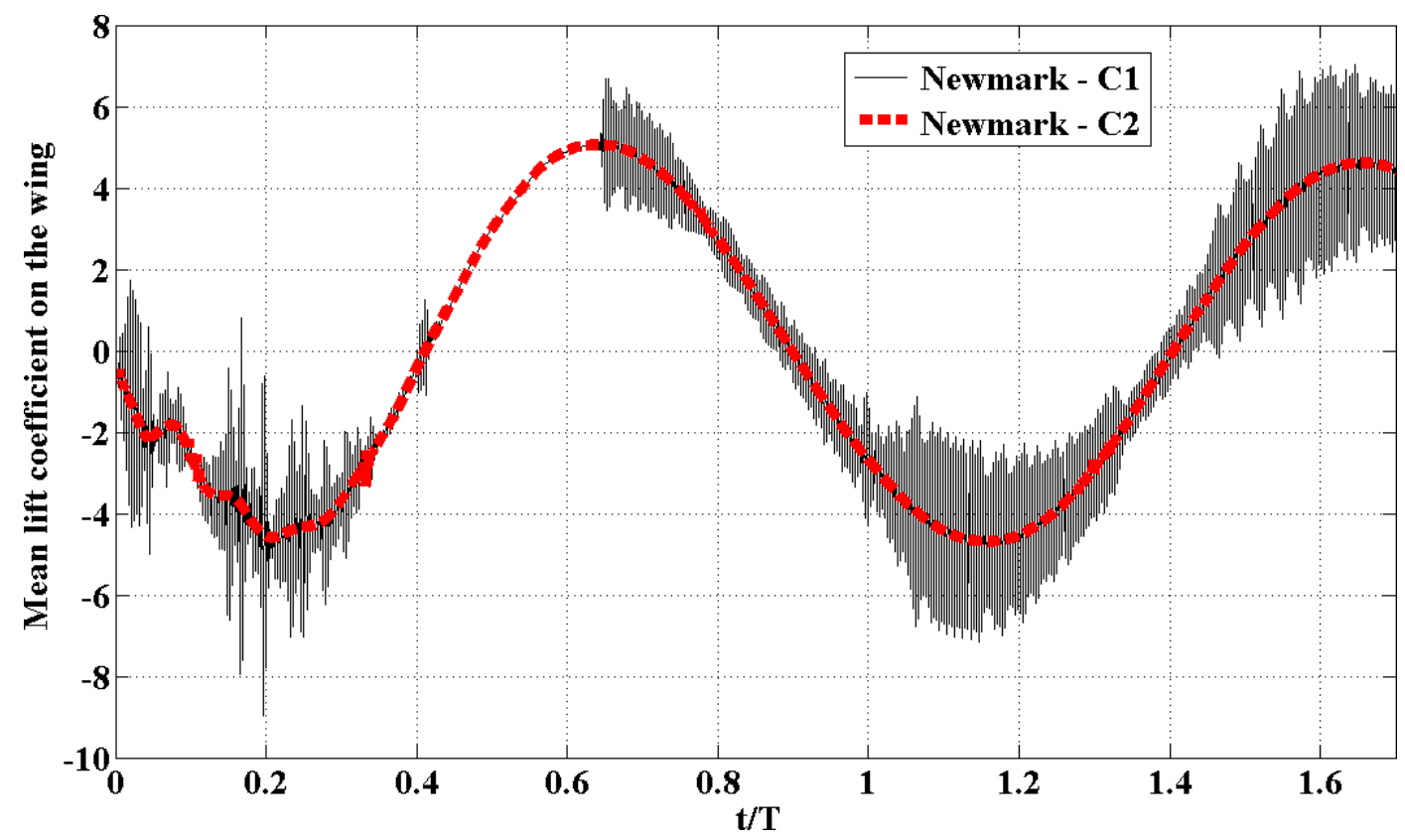

Figure 21. Lift coefficient on the plunging wing with two different convergence criteria.

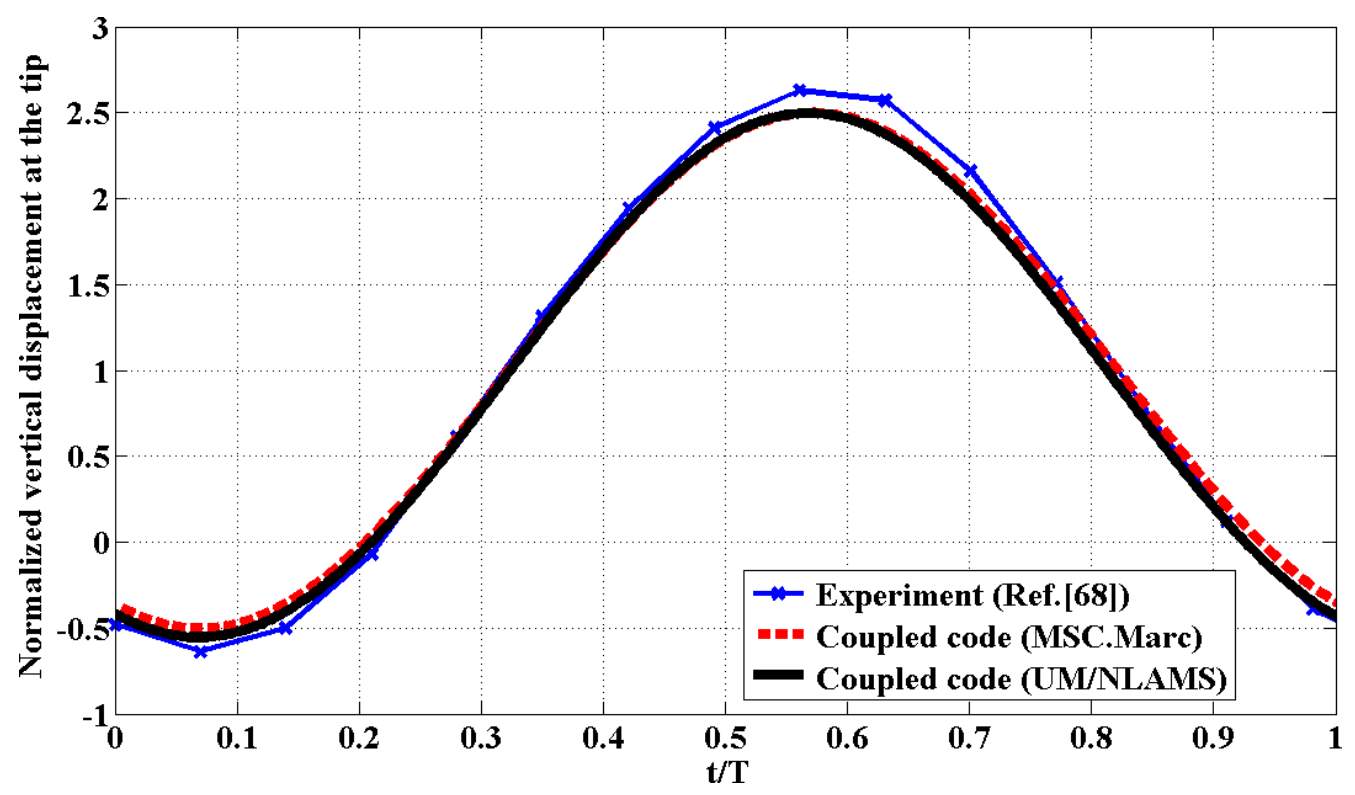

Figure 22. Aeroelastic response of a flexible rectangular wing under pure plunge motion. 


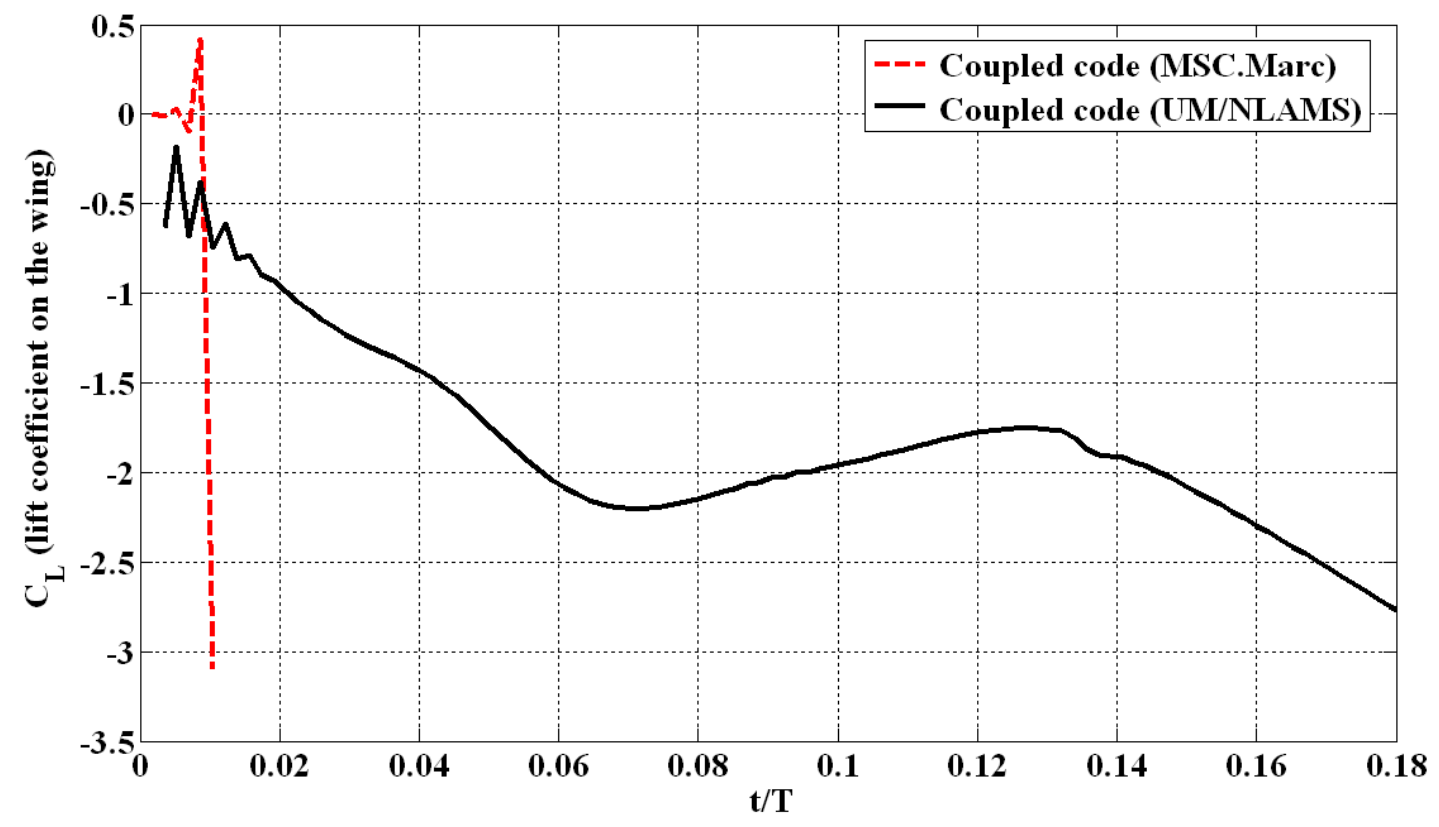

Figure 23. Lift coefficient on the highly flexible aluminium wing (the response computed with MSC.Marc is scaled by a factor of 100 for visualization purposes).

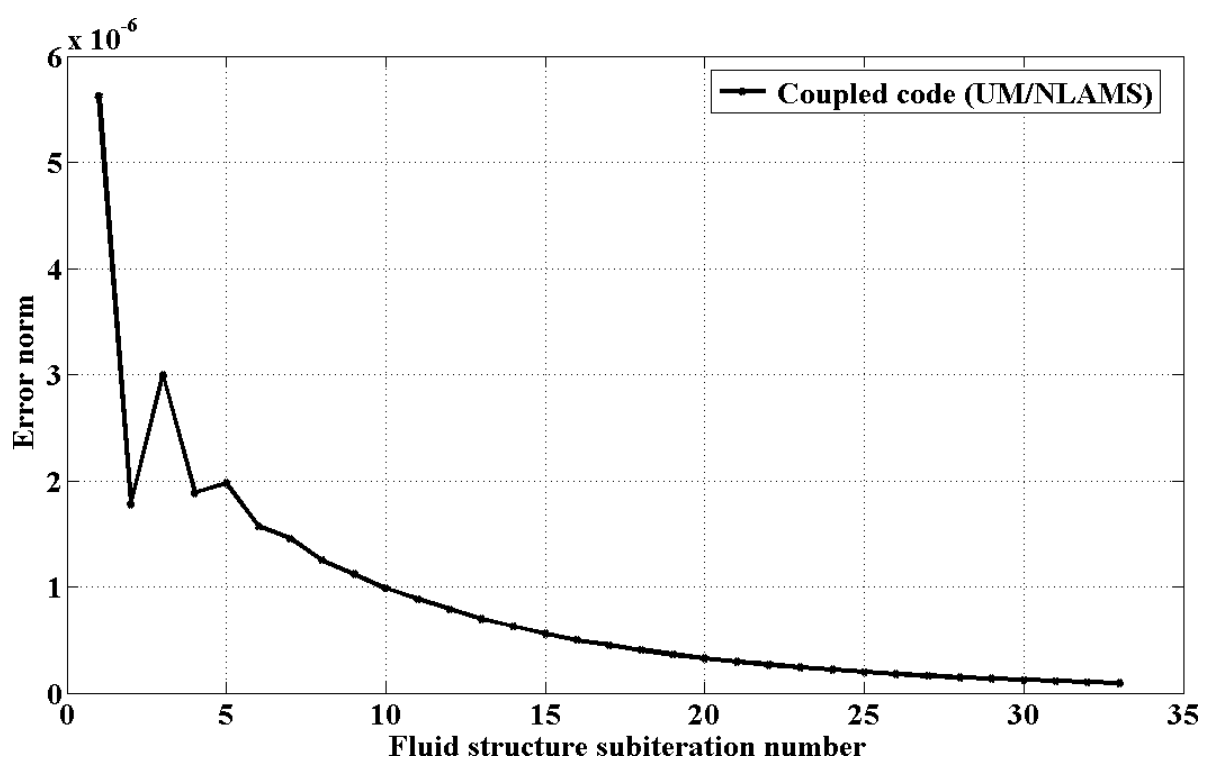

Figure 24. Aeroelastic convergence within the first coupled time step.

\section{Acknowledgments}

The authors would like to thank Mr. Pin Wu and Prof. Peter Ifju (University of Florida) for providing the experimental data for the aeroelastic analysis of flapping wing in this work. This work was supported by the Air Force Office of Scientific Research's Multidisciplinary University Research Initiative (MURI) grant and by the Michigan/AFRL (Air Force Research Laboratory)/Boeing Collaborative Center in Aeronautical Sciences. 


\section{References}

1. Shyy, W., Lian, Y., Tang, J., Viieru, D., Liu, H., "Aerodynamics of Low Reynolds Number Flyers," Cambridge University Press, New York, 2008.

2. Shyy, W., Berg, M., and Ljungqvist, D., "Flapping and Flexible Wings for Biological and Micro Air Vehicles," Progress in Aerospace Sciences, Vol. 35, No. 5, 1999, pp. 455-505.

3. Mueller, T., ed. Fixed and Flapping Wing Aerodynamics for Micro Air Vehicle Applications. Progress in Aeronautics and Astronautics. Vol. 195. 2001, AIAA: New York.

4. Pines, D., Bohorquez, F., "Challenges Facing Future Micro Air Vehicle Development," Journal of Aircraft, Vol. 43, No. 2, 2006, pp. 290-305.

5. Wootton, J., "Support and Deformability in Insect Wings," Journal of Zoology, Vol. 193, No., 1981, pp. 447-468.

6. $\quad$ Frampton, K., Goldfarb, M., Monopoli, D., Cveticanin, D., ed. Passive Aeroelastic Tailoring for Optimal Flapping Wings. Fixed and Flapping Wing Aerodynamics for Micro Air Vehicle Applications, ed. T.J. Mueller. Vol. 195. 2001. 473-482.

7. Kim, D.K., Lee, J.S., Lee, J.Y., and Hung, J., "An Aeroelastic Analysis of a Flexible Flapping Wing Using Modified Strip Theory," Proceedings of Active and Passive Smart Structures and Integrated Systems, San Diego, California, 4 April, 2008.

8. Wills, D., Israeli, E., Persson, P., Drela, M., Peraire, J., Swartz, S.M., and Breuer, K.S., "A Computational Framework for Fluid Structure Interaction in Biologically Inspired Flapping Flight," 25th AIAA Applied Aerodynamics Conference, Miami, Florida, 25-28 June 2007.

9. Aono, H., Chimakurthi, S.K., Cesnik, C.E.S., Liu, H., and Shyy, W., "Computational Modeling of Spanwise Flexibility Effects on Flapping Wing Aerodynamics," 47th AIAA Aerospace Sciences Meeting Including The New Horizons Forum and Aerospace Exposition, Orlando, Florida, 5-8 Jan, 2009.

10. Chimakurthi, S.K., Tang, J., Palacios, R., Cesnik, C.E.S., Shyy, W., "Computational Aeroelasticity Framework For Analyzing Flapping Wing Micro Air Vehicles," 49th AIAA/ASME/ASCE/AHS/ASC Structures, Structural Dynamics, and Materials Conference, Schaumburg, IL, 7-10 April 2008, 2008.

11. Tang, J., Chimakurthi, S.K., Palacios, R., Cesnik, C.E.S., and Shyy, W., "Fluid-Structure Interactions of Three-Dimensional Deformable Flapping Wing For Micro Air Vehicle Applications," 46th AIAA Aerospace Sciences Meeting and Exhibit, Reno, Nevada, 7-10 Jan 2008.

12. Hamamoto, M., Ohta, Y., Hara, K., and Hisada, T., "Application of Fluid-Structure Interaction Analysis to Flapping Flight of Insects with Deformable Wings," Advanced Robotics, Vol. 21, No. 1-2, 2007, pp. 1-21.

13. Smith, M.J.C., "The Effect of Flexibility on the Aerodynamics of Moth Wings: Towards the Development of Flapping-Wing Technology," 33rd Aerospace Sciences Meeting and Exhibit, Reno, Nevada, 1995.

14. Singh, B., "Dynamics and Aeroelasticity of Hover Capable Flapping Wings: Experiments and Analysis," Aerospace Engineering, University of Maryland, College Park, MD, 2006.

15. Ho, S., Nassef, H., Pornsinsirirak, N., Tai, Y.C., and Ho, C.H., "Unsteady Aerodynamics and Flow Control for Flapping Wing Flyers," Progress in Aerospace Sciences, Vol. 39, No., 2003, pp. 635-681.

16. Liani, E., "Potential Flow Based Aerodynamic and Aeroelastic Analysis of Flapping Wings," Cranfield University, March 2008.

17. Ke, S., Zhigang, W., and Chao, Y., "Analysis and Flexible Structural Modeling for Oscillating Wing Utilizing Aeroelasticity," Chinese Journal of Aeronautics, Vol. 21, No. 5, Oct 2008, pp. 402-410.

18. Gogulapati, A., Friedmann, P.P., and Shyy, W., "Nonlinear Aeroelastic Effects in Flapping Wing Micro Air Vehicles," 49th AIAA/ASME/ASCE/AHS/ASC Structures, Structural Dynamics, and Materials Conference, Schaumburg, IL, 7-10 April 2008.

19. Unger, R., Haupt, M.C., and Horst, P., "Structural Design and Aeroelastic Analysis of an Oscillating Foil for Flapping Wing Propulsion," 46th AIAA Aerospace Sciences and Exhibit, Reno, Nevada, 7-10 January 2008.

20. Yang, H.Q., "A Reduced Order Method for Grid Deformation in Aeroelasticity Analysis," 47th AIAA Aerospace Sciences Meeting Including The New Horizons Forum and Aerospace Exposition, Orlando, Florida, 5-8 Jan 2009.

21. Shyy, W., Udaykumar, H., Rao, M., and Smith R., "Computational Fluid Dynamics with Moving Boundaries," Dover, New York, 2007.

22. Causin, P., Gerbeau, J.F., and Nobile, F., "Added-mass Effect in the Design of Partitioned Algorithms for Fluid-Structure Problems," Computational Methods in Applied Mechanics and Engineering, Vol. 194, No. 42-44, 2005, pp. 4506-4527. 
23. Battini, J., Pacoste, C., "On the Choice of Local Element Frame for Co-rotational Triangular Shell Elements," Communications in Numerical Methods in Engineering, Vol. 20, No., 2004, pp. 819-825.

24. Battini, J.M., "A Modified Co-rotational Framework for Triangular Shell Elements," Computer Methods for Applied Mechanics and Engineering, Vol. 196, No., 2007, pp. 1905-1914.

25. Crisfield, M., Galvanetto, U., Jelenic, G., "Dynamics of 3-D Co-rotational Beams," Computational Mechanics, Vol. 20, No., 1997, pp. 507-519.

26. Devloo, P., Geradin, M., Fleury, R., "A Co-rotational Formulation for the Simulation of Flexible Mechanisms," Multibody System Dynamics, Vol., No. 4, 2000, pp. 267-295.

27. Elkaranshawy, H.A., Dokainish, M.A., "Co-rotational Finite Element Analysis of Planar Flexible Multibody Systems," Computers and Structures, Vol. 54, No. 5, 1995, pp. 881-890.

28. Jiang, L., Michael, W.C., and Pegg, N.G., "A Co-rotational, Updated Lagrangian Formulation for Geometrically Nonlinear Finite Element Analysis of Shell Structures," Finite Elements in Analysis and Design, Vol. 18, No., 1994, pp. 129-140.

29. Khosravi, P., Ganesan, R., and Sedaghati, R., "Co-rotational Nonlinear Analysis of Thin Plates and Shells Using a New Shell Element," International Journal of Numerical Methods in Engineering, Vol. 69, No., 2007, pp. 859-885.

30. Khosravi, P., Ganesan, R., and Sedaghati, R., "An Efficient Facet Shell Element for Co-rotational Nonlinear Analysis of Thin and Moderately Thick Laminated Composite Structures," Computers and Structures, Vol. 86, No., 2008, pp. 850-858.

31. Mattiasson, K., and Samuelson, A., "Total and Updated Lagrangian Forms of the Co-rotational Finite Element Formulation in Geometrically and Materially Nonlinear Analysis," Proceedings of Numerical Methods for Non-linear Problems, Universidad Politecnica de Barcelona, April 1984.

32. Pacoste, C., "Co-rotational Flat Facet Triangular Elements for Shell Instability Analysis," Computer Methods in Applied Mechanics and Engineering, Vol. 156, No. 1-4, 1998, pp. 75-110.

33. Rankin, C., Consistent Linearization of the Element-Independent Co-rotational Formulation for the Structural Analysis of General Shells, in. Jan 1988.

34. Rankin, C.C., and Brogan, F.A., "An Element Independent Co-rotational Procedure for the Treatment of Large Rotations," ASME Journal of Pressure Vessel Technology, Vol. 108, No., 1991, pp. 165-174.

35. Relvas, A., and Suleman, A., "Application of the Co-rotational Structural Kinematics and Euler Flow to Two Dimensional Nonlinear Aeroelasticity," Computers and Structures, Vol. 85, No., 2007, pp. 13721381.

36. Zhong, H.G., and Crisfield, M.A., "An Energy-Conserving Co-rotational Procedure for the Dynamics of Shell Structures," Engineering Computations, Vol. 15, No. 5, 1997, pp. 552-576.

37. Gal, E., and Levy, R., "Geometrically Nonlinear Analysis of Shell Structures Using a Flat Triangular Shell Finite Element," Archives of Computational Methods in Engineering, Vol. 13, No. 3, 2006, pp. 331-388.

38. Wasfy, T., "Modeling Continuum Multibody Systems Using the Finite Element Method and Element Convected Frames, Machine Elements, and Machine Dynamics," Proceedings of 23rd ASME Mechanisms Conference, 1994.

39. Relvas, A., and Suleman, A., "Fluid Structure Interaction Modelling of Nonlinear Aeroelastic Structures Using the Finite Element Corotational Theory," Journal of Fluids and Structures, Vol. 22, No. 1, January 2006, pp. 59-75.

40. Wasfy, T., "Computational Strategies for Flexible Multibody Systems," Applied Mechanics Review, Vol. 56, No. 6, Nov 2003, pp. 553-613.

41. Barut, A., Das, M., and Madenci, E, "Nonlinear Deformations of Flapping Wings on a Micro Air Vehicle," 47th AIAA/ASME/ASCE/AHS/ASC Structures, Structural Dynamics, and Materials Conference, Newport, Rhode Island, 1-4 May 2006.

42. Farhat, C., and Lesoinne, M., "Enhanced Partitioned Procedures for Solving Nonlinear Transient Aeroelastic Problems," 39th AIAA/ASME/ASCE/AHS/ASC Structures, Structural Dynamics, and Materials Conference, Long Beach, CA, April. 20-23, 1998.

43. Piperno, S., Farhat, C., and Larrouturou, B., "Partitioned Procedures for the Transient Solution of Coupled Aeroelastic Problems Part I: Model Problem, Theory, and Two-dimensional Application," Computer Methods for Applied Mechanics and Engineering, Vol. 124, No. 1-2, June 1995, pp. 79-112.

44. Smith, M.J., Hodges, D.H., and Cesnik, C.E.S., "Evaluation of Computational Algorithms Suitable for Fluid-Structure Interactions," Journal of Aircraft, Vol. 37, No. 2, March-April 2000, pp. 282-294.

45. Press, W.H., Vetterling, W.T., Teukolsky, S.A., and Flannery, B.P., "Numerical Recipes: The Art of Scientific Computing," Cambridge University Press, 2007. 
46. Thomas, P., and Lombard, K., "Geometric Conservation Law and its Applications to Flow Computations on Moving Grids," AIAA Journal, Vol. 17, No. 10, 1979, pp. 1030-1037.

47. Hartwich, P.M., and Agrawal, S., "Method for Perturbing Multiblock Patched Grids in Aeroelastic and Design Optimization Applications," AIAA Computational Fluid Dynamics Conference, Snowmass Village, CO, 1997.

48. Kamakoti, R., and Shyy, W., "Evaluation of Geometric Conservation Law Using Pressure-based Fluid Solver and Moving Grid Technique," International Journal of Numerical Methods for Heat and Fluid Flow, Vol. 14, No. 7, 2004, pp. 851-865.

49. Lian, Y., "Membrane and Adaptively-Shaped Wings for Micro Air Vehicles," Mechanical and Aerospace Engineering, University of Florida, Gainesville, FL, 2003.

50. Tsang, T., "Dynamic Analysis of Highly Deformable Bodies Undergoing Large Rotations," The University of Arizona, 1993.

51. Mattiasson, K., Bengtsson, A., and Samuelson, A., "On the Accuracy and Efficiency of Numerical Algorithms for Geometrically Nonlinear Analysis," Finite element Methods for Nonlinear Problems: Europe-US Symposium, 1986.

52. Meek, J.L., and Wang, Y., "Nonlinear Static and Dynamic Analysis of Shell Structures with Finite Rotations," Computer Methods for Applied Mechanics and Engineering, Vol. 162, No., 1998, pp. 301-315.

53. de Veubeke, B., "The Dynamics of Flexible Bodies," International Journal of Engineering Science, Vol. 14, No., 1976, pp. 895-913.

54. Nygard, M., "The Free Formulation for Nonlinear Finite Elements with Applications to Shells," Structural Mechanics, NTH, Trondheim, Norway, 1986.

55. Argyris, J., "An Excursion into Large Rotations," Computer Methods in Applied Mechanics and Engineering, Vol. 32, No. 1-3, Sep 1982, pp. 85-155.

56. Geradin, M., and Cardona, A., "Flexible Multibody Dynamics: A Finite Element Approach," Wiley, March 2001.

57. Zienkiewicz, O.C., and Taylor, R.L., "The Finite Element Method," Elsevier Butterworth-Heinemann, Burlington, MA, 2005.

58. Felippa, C.A., "A Study of Optimal Membrane Triangles with Drilling Freedoms," Computer Methods in Applied Mechanics and Engineering, Vol. 192, No. 16-18, April 2003, pp. 2125-68.

59. Batoz, J.L., Bathe, K.J., and Ho, L.W., "A Study of Three-Node Triangular Plate Bending Elements," International Journal for Numerical Methods in Engineering, Vol. 15, No. 12, Dec 1980, pp. 1771-1812.

60. Cook, R.D., Malkus, D.S., Plesha, M.E., and Witt, R.J., "Concepts and Applications of Finite Element Analysis," John Wiley \& Sons, New York, 2002.

61. Nour-Omid, B., and Rankin, C., "Finite Rotation Analysis and Consistent Linearization Using Projectors," Computer Methods for Applied Mechanics and Engineering, Vol. 93, No., 1991, pp.

62. Chung, J., and Hulbert, G., "A Time Integration Algorithm for Structural Dynamics with Improved Numerical Dissipation: The Generalized-alfa Method," Journal of Applied Mechanics, Vol. 60, No. 2, June 1993, pp. 371-375.

63. Shearer, C.M., and Cesnik, C.E.S., "Modified Generalized-alfa Method for Integrating Governing Equations of Very Flexible Aircraft," 47th AIAA/ASME/ASCE/AHS/ASC Structural, Structural Dynamics, and Materials Conference, Newport, Rhode Island, 1-4 May, 2006.

64. Subbaraj, K., and Dokainish, M.A.A, "Survey of Direct Time-Integration Methods in Computational Structural Dynamics: II. Implicit Methods," Computers and Structures, Vol. 32, No. 6, 1989, pp. 13871401.

65. Shyy, W., "Computational Modeling for Fluid Flow and Interfacial Transport," Elselvier, Amsterdam, The Netherlands, 1994.

66. Hsiao, K.M., "Nonlinear Analysis of General Shell Structures by Flat Triangular Shell Element," Computers and Structures, Vol. 25, No. 5, 1987, pp. 665-675.

67. Wu, P., Stanford, B., and Ifju, P., "Passive Bending and Twisting Motion during the Flapping Stroke of a Micro Elastic Wing for Thrust Production," AIAA Aerospace Sciences Meeting, Orlando, FL, 5-8 January, 2009.

68. Heathcote, S., Wang, Z., and Gursul, I., "Effect of Spanwise Flexibility on Flapping Wing Propulsion," Journal of Fluids and Structures, Vol. 24, No. 2, 2008, pp. 183-199. 